\title{
آلية الادراك والمتخيل في اللوحة الفنية
}

م.م سحر عبد الكاظم غانم

الجامعة المستنصرية/ مديرية الانشطة القنية

\section{الملخص:}

إنّ عملية تشكيل روية فنية منكاملة تتطلق عبر تكوين رموز شكلية متتاسقة في اللوحة الفنية ، وذللك عبر

تشكيل احداث نوافقية وتواصل بين الخيال وادراك المفاهيم الفنية الني يسعى اليها الفنان في بناء منظومة مكتملة من التكوينات والصور الحسية التي يدركها المتلقي ، ليشكل بنية مفاهيمية منواصلة لنتكيلات صورية ترتبط بين الخيال الذي يمتلكه الفنان وبين العمل الفني وقدرة المتلقي في فلك رموز اللوحة والتعبير عن اللذة التي يشعر بها لهابها عبر احاسيس منرابطة تؤثر في ادراك الثكل النهائي للعمل الفني. ولهذا نجد ان عملية الادراك والخيال صفتان متلازمنان في عملية تحليل وتركيب اللوحة الفنية لما تتمتع بها تلك فيك العمليات العقلية في فهم كل التفاصيل التي يسعى الفنان ايصالها الى المتلقي ـ وقد صيغت مشكلة البحث الحالي في التساؤل الآتي: (ما الكيفية التي بموجبها التي يتجسد الادراك والمخيل في اللوحة الفنية؟) اما هدف البحث الحالي؛ فهو (ماهي الكيفيات التي توظف فيها عملية الادراك والمتخيل في اللوحة الفنية) وقد تضمن الاطار النظري المباحث الأتية :

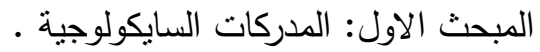
المبحث الثاني: المتخيل مفهومه ووظائفه. المبحث الثالث: آلية اثتغال المتخيل

\section{الفصل الاول/ الاطار المنهجيّ:

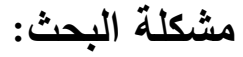

إنّ الفن التشكيلي كثيرا ما ينزع نحو التعقيد والتركيب في تشكيل بنيته الفنية التي تتداخل مع العناصر السايكولوجية فيها بعضها مع البعض، من هنا فان الفنان التشكيلي يخلق صورته الفنية حتى قبل ان يبدأ عمله المباشر مـع المـادة انه يخلقها في المخيلة ومـع ذلك فان الابداع المتخيل مرتبط منذ البدايـة ارتباطا شديدا بالتصـورات حول تلك العناصـر والمفردات التي سيتم بواسطتها تجسيد تلك الصورة المتخيلة وذلك من خلال عمليات الادرالك الحسي حيث تكمن الخطوة الاولى لانجاز اللوحة الفنية التي تعتمد على المعلومة التي تصل عن طريق الحواس، مثل البصر تخليق ادراكات الفنـان وهذه الصـور الحسية المعبرة التي ينتقيها مـن الواقـع المـادي ليست شـرطا لازمـا للثيء المدرك (المنتفي) بل يمكن الافادة من الاشياء غير المادية كالمعنويات، فالمعنوي يمكن ان يصبح موضوعا وعلى هذا الاسـاس فان توظيف المدركات السـايكولوجية من خـلال بنـاء صسورة ذهنية داخل الذاكرة لغرض تجسيدها من خلال رؤية فنية تحمل سمات جمالية مبدعة عبر خلق عوالم جديدة تتسم بغرائبيتها وفنتازياتها ضدمن الواقع الجديد المفترض الذي يعيد تشكيلة الفنـان 
وعملية اعادة خلق الواقع على وفق معطيات جديدة قادرة على بلورة عوالم تحمل سمات جديدة

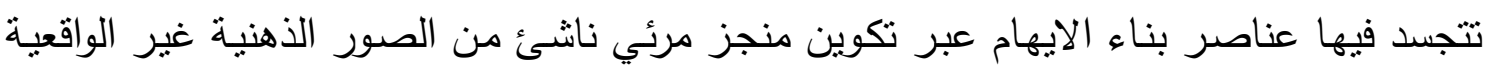

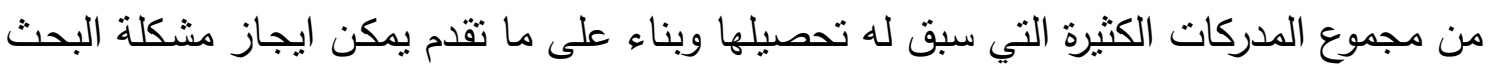

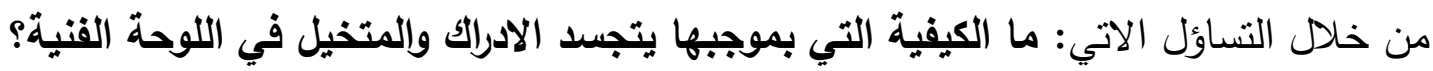

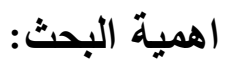

هذا البحث هو محاولية لتفسير وفهم كيفيات تجسيد الادراك والمتخيل في اللوحة الفنية والتي تكمن اهميتها في كونها تنكل بعدا في عملية الخلق داخل اللوحة الفنية وكذلك تشليط الضوء

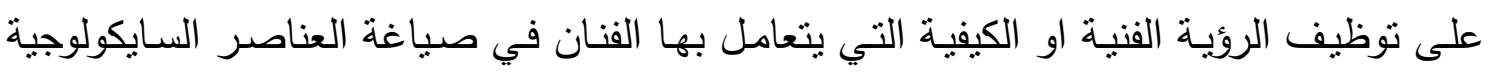
والادوات الفنية لتكوين المنجز المرئي. نظرا لافتقار المكتبـة الاكاديميـة الى دراسـات سـايكوفنية

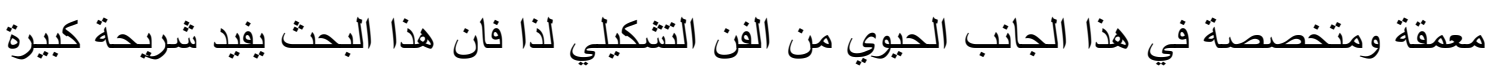

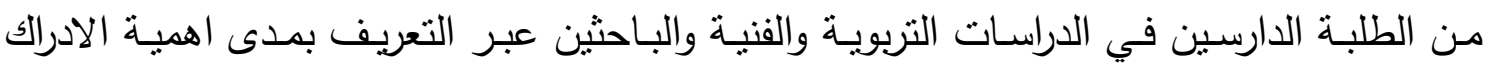
والمتخيل في اللوحة الفنية.

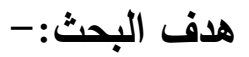

يهدف البحث الحالي الى دراسة الكيفيات التي نوظف فيها الادراك والمتخيل في اللوحـة

$$
\text { يتحدد البنة. }
$$

1. الحد الموضوعي:- المتمثل في دراسة آلية الادراك والمتخيل في اللوحة الفنية.

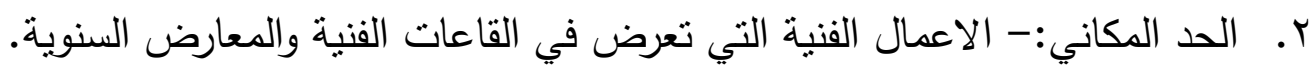
تحديد المصطلحات:-

تتــر ادبيـات علـم الـنفس الـى كـم مـن التحديـدات والتعريفـات الخاصــة بـالادراك الحسـي - perception

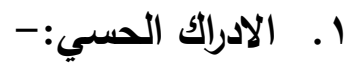
ويعرف بانه (قدرة الكائن العضوي على الفهم من خلال الاستجابة لاعضائه الحسية ويتم من

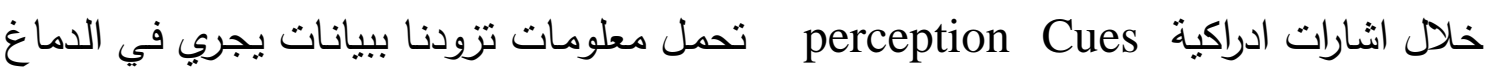
تتظيمها وتفسيرها بخصوص العالم من حولنا ويعد الادراك البصري هو الاعظم اهميـة بالنسبة

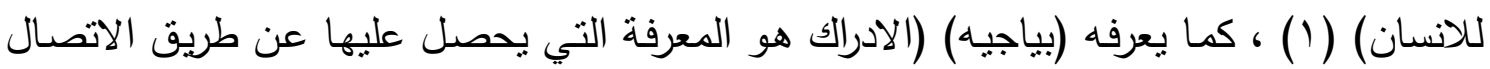

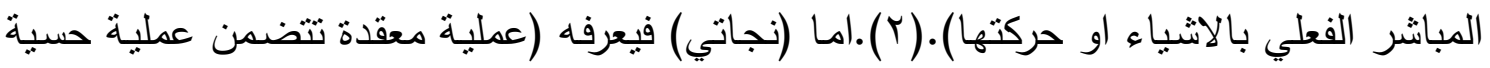

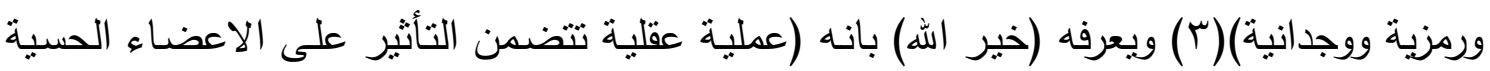


بمؤثرات معينة ويقوم الفرد باعطاء تفسير وتحديد لهذه المؤثرات في شكل رموز او معان بما يسهل

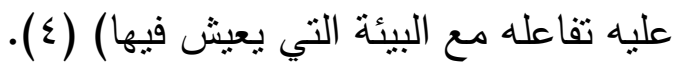

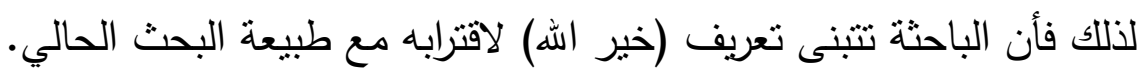

$$
\text { يعرفه (الجرجاني) المتخيل كما يلي:- المتخيل:- }
$$

(ا. القدرة للتصوير أي القدرة التي تتشكل الصسور والافكار في العقل من خـله الاثثياء

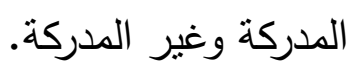

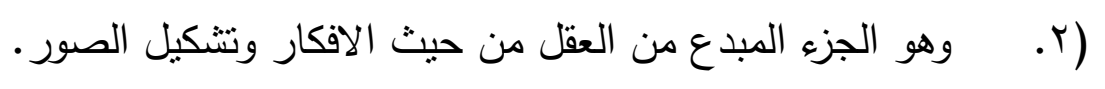

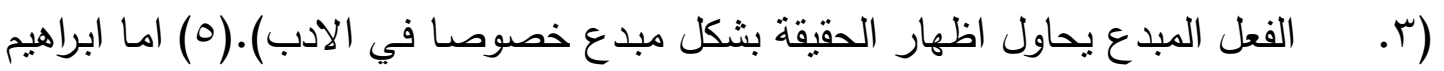

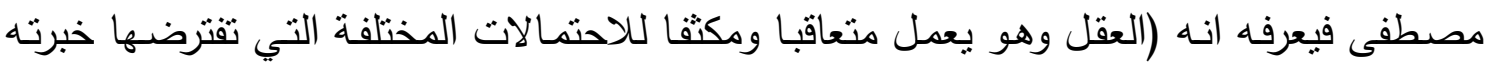

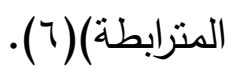

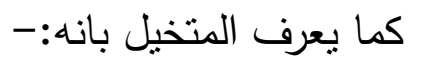

ا. القدرة المسؤولة عن استحضار الصور المرئية مفردة او مجتمعة في الذهن.

$$
\text { r r القدرة على توليف هذه الصور نوليفا جذابا. }
$$

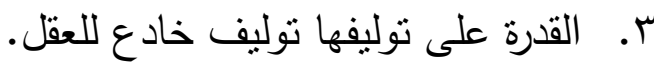

ء. قدرة الفنان على اسقاط مشاعره فوق موقف و شخصية اسقاط ينتج عن التفاعل المتعاطف

ه. الملكة التي تمكن الذهن من ابداع رموز للمفهومات المجردة.

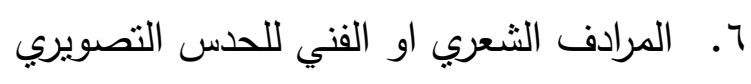

V. قدرة الانسان على تشكيل مالا شكل له من غير تدخل من ناحيته). (V)

$$
\text { وعليه تجد الباحثة ان:- }
$$

التعريف الاجرائي للمتخيل هو القوة التي تكون صورا تتصف بالاصالة والابتكار غير المألوفة في الواقع ثم توظيفها بشكل يتلاءم وطبيعة اللوحة الفنية.

الفصل الثاني/الاطار النظريّ: المبحث الاول/المدركات السايكولوجية: النطان:

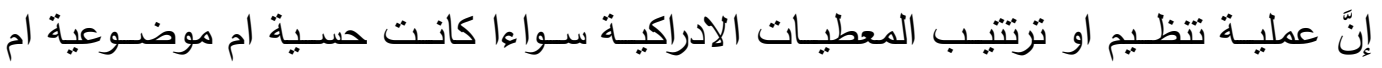

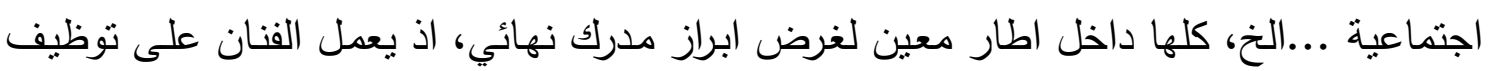


العناصر الفنية التي تدخل في تكوين اللوحة الفنية وما تحمله من صفات جمالية من خلال تحليل وتركيب الصور الحسية من اجل التأثير في المتلقي وبذلك يكون للفنان قدرته الابداعية في تفسير

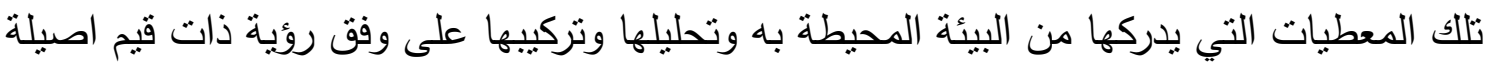
من خلال استحضار نتلك الصور الذهنية الددركة سابقا وتوظيفها ومن خلال ما يمتلكها من خيال

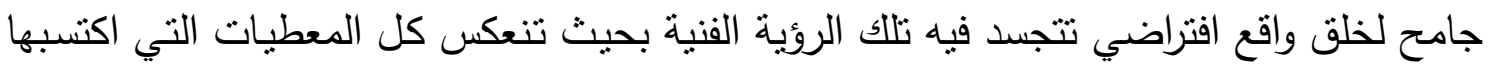
وكون عنها مفهوما ورؤية جديدة مفسرة يعكسها من خلال اللوحة الفنية.

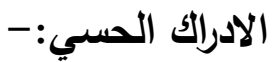

ان محاولة التعرف على الجانب البصري كونه يعد اهم الحواس الذي لهه وظيفة مساعدة لعطلية

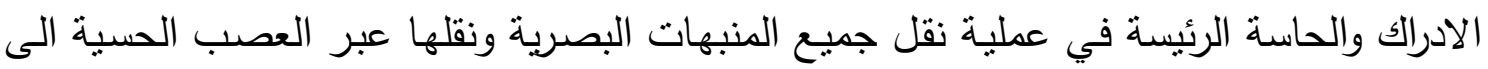

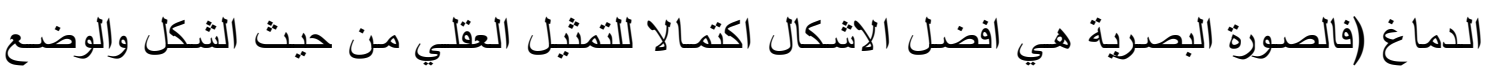

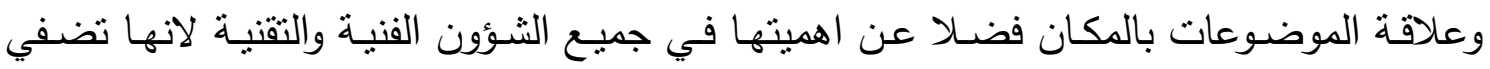

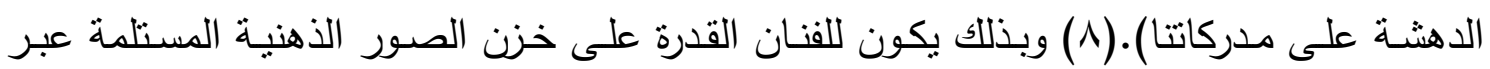

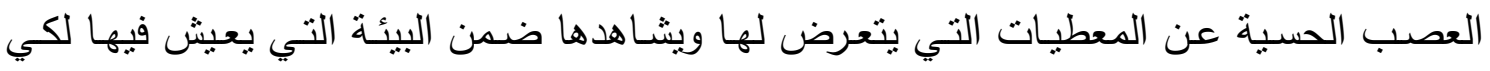
يوظفها لاحقا من خلال تكامل وتحليل وتركيب تلك الصور خلال اللوحة الفنية عبر بناء ومشاكلة

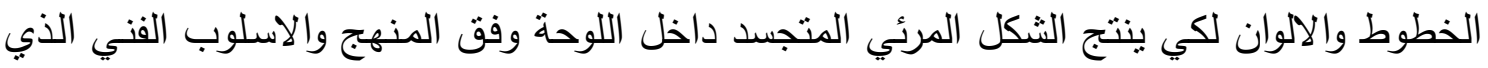
ينتهجه الفنان عند صياغة عناصره الفنية لان (الادراك البصري بوصفه اقوى المؤثرات الحسية فهو

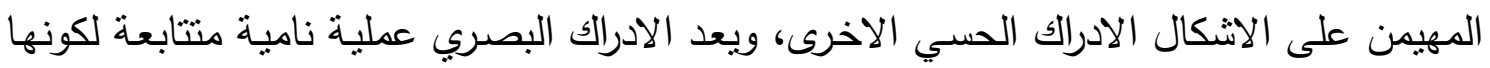

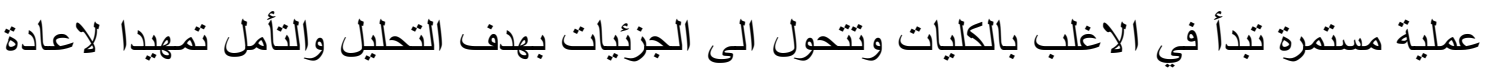

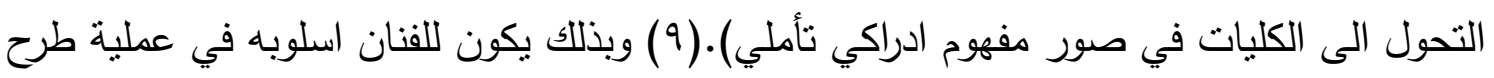
المعلومات بحيث يجعل المتلقي يستخلص الخاص من العام من خلال قيادته الى ادق التفاصيل

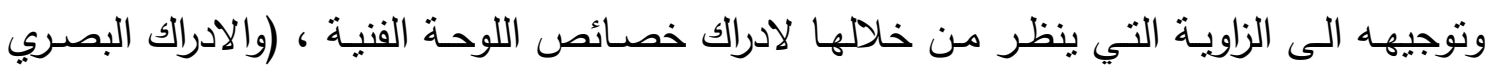

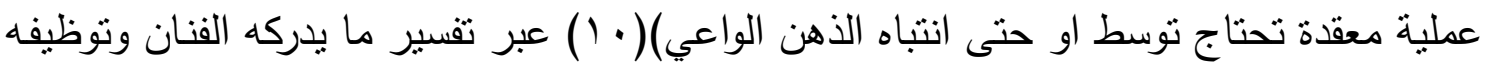

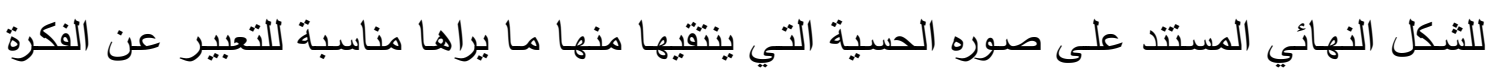
ومضمون العمل لفني ، ويطلق (الادرالك الحسي على تمثيل الثنيء الخارجي وحده فيقولون ان هذا

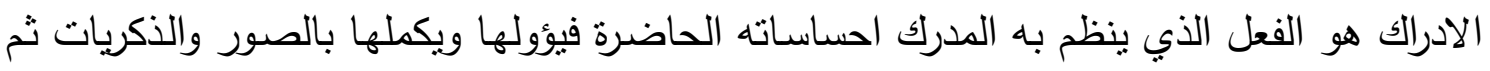

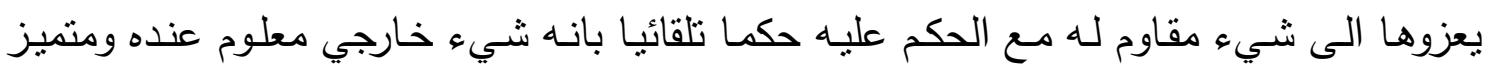
عنه)(1 (1) ، وبهذا يعمل الفنان على استحضار الصور الذهنية المدركة سابقا ومن خلال خياله

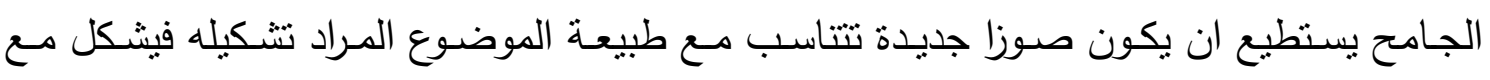

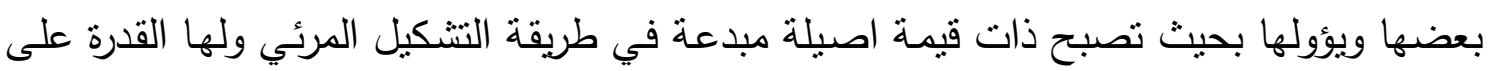


التأثثر في المتلقي، (والادراك الحسي فهو ادراك الثيء تثؤثر كيفيته في الحس وذلك بالاستعانة

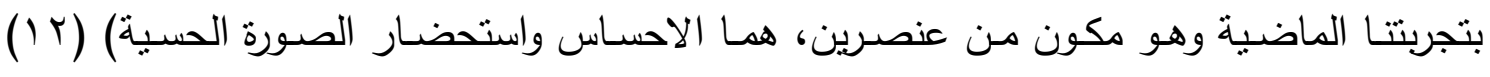

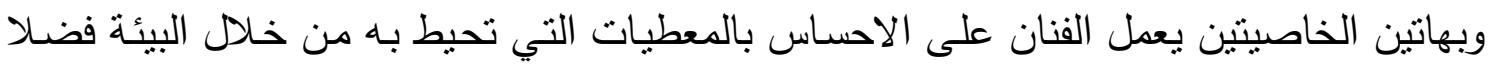

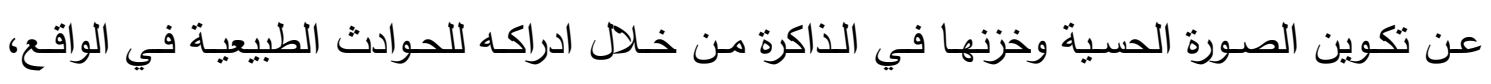

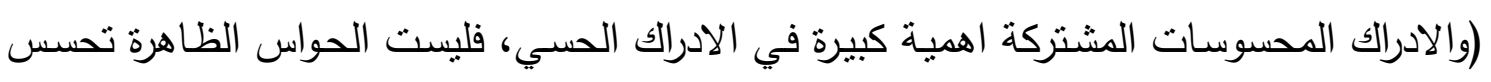

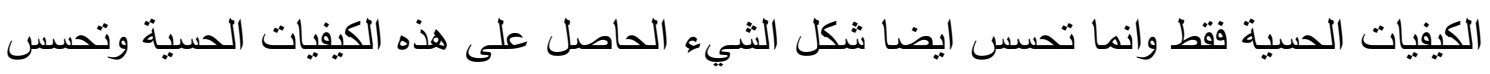

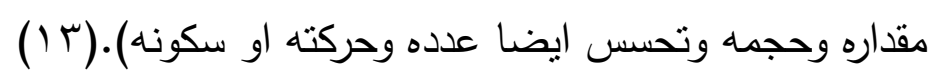
خصائص الادراك: -

يتميز ادراك الانسـان بعدد من الخصـائص التـي تجعله يختلف عن سـائر الكائنـات الاخـرى . مهي:- مادرئ.

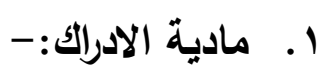

تتجلى ماديـة الادراك في قدرة الانسـان على ارجـاع المعلومـات الـواردة اليـهـ مـن العـالم

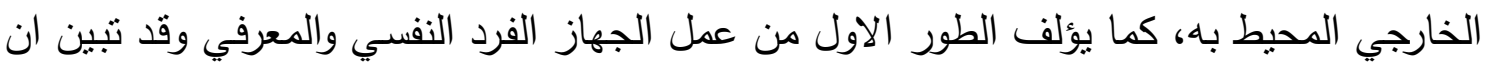
الخاصية المادية للإدراك ليست خاصية نظرية بل هي صفة يكتسبها الفرد في سياق نموه وتتكون

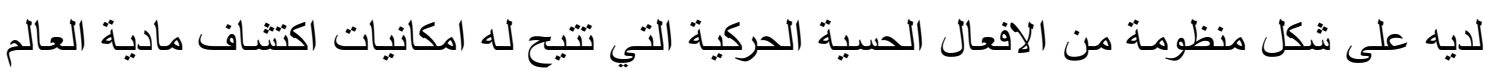

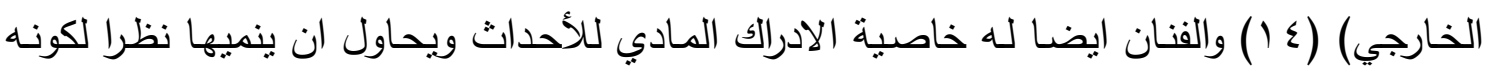
يحتاج الى اكبر خزين معرفي وحسي بما يخدم مسيرته الفنية.

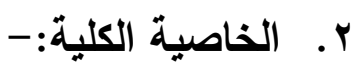

تمثل صورة كلية ناجمة من تتظيم الاحساسات في شكل او نمط و بنية متماسكة واظهار

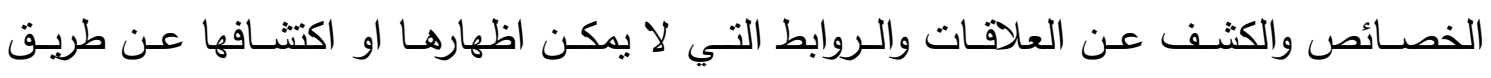

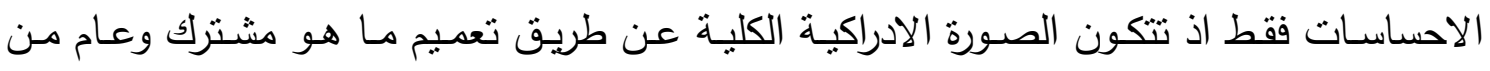
الصفات والخصائص لفنه او صنف من الموضون التوعات).(10) r. - الخاصية الايناميكية وقابلية التوجه:-

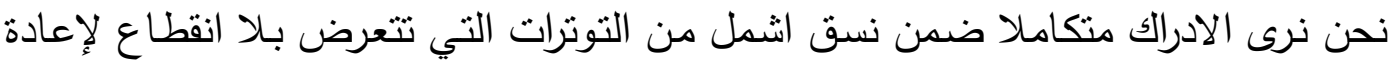

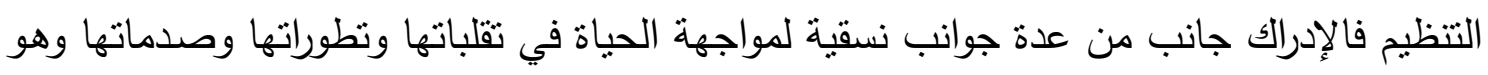

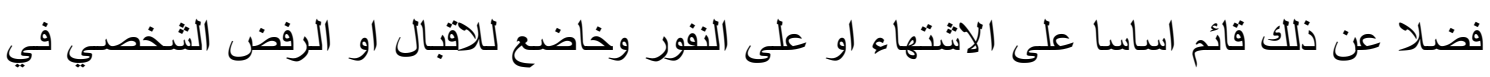

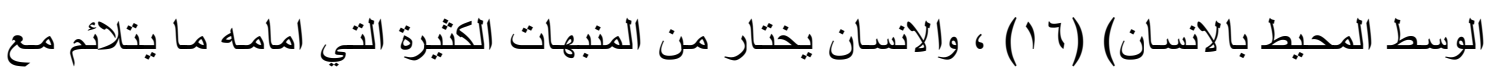

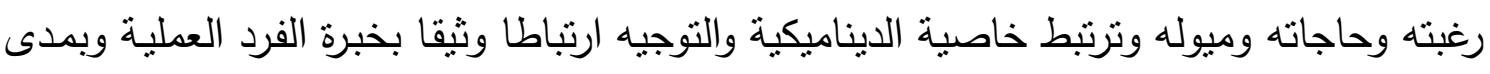
فاعليته في النشاط الادراكي فالاختصاص في مجال الرسم مثلا، عندما ينظر الى لوحة فنية ونية معينة 
بقصد تحديد الاسلوب الذي اتبعه الفنان في رسمها فانه يتغاضى عن مضمونها لانه يحاول بصورة

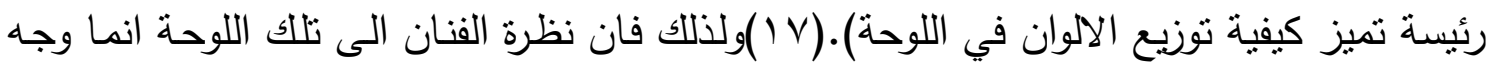

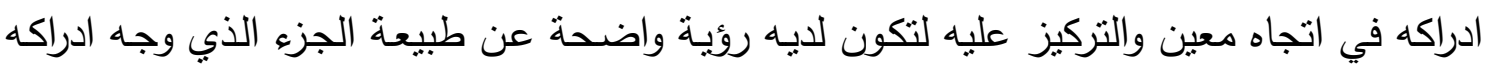

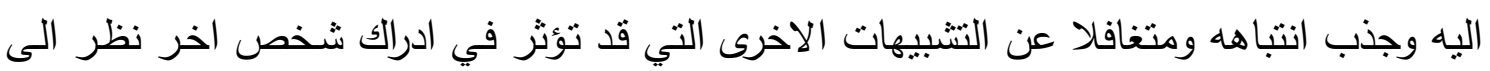
نفس اللوحة او أي شيء يمكن ان يجتذب الانتباه ويوجه المدركات الحسية اليه.

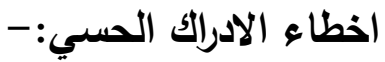

بثكل عام ينسب علماء النفس اخطاء الادرالك الحسي الى ادراك المحسوسات العرضية كون المحسوسات تتقسم الى (ذاتية وعرضية).

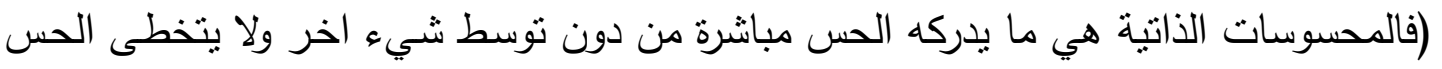

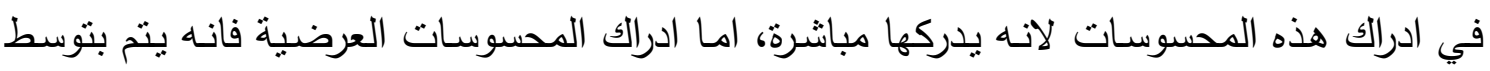

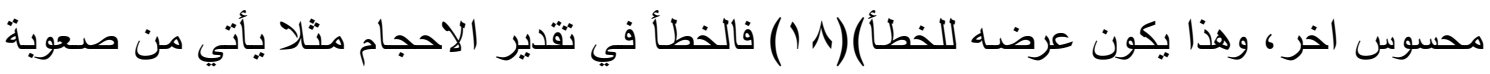

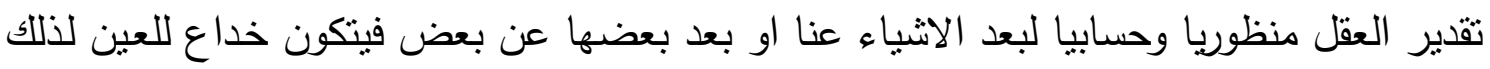

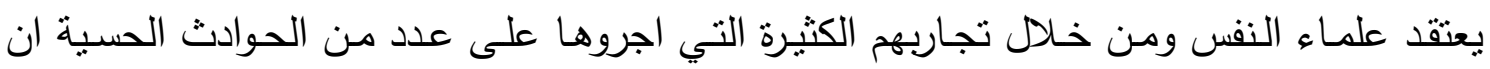

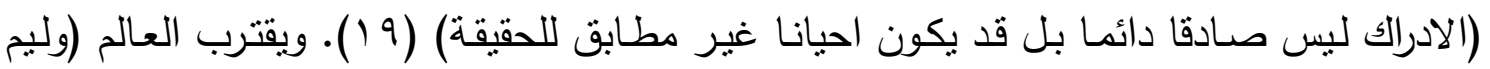

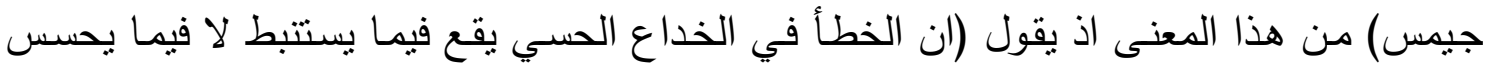

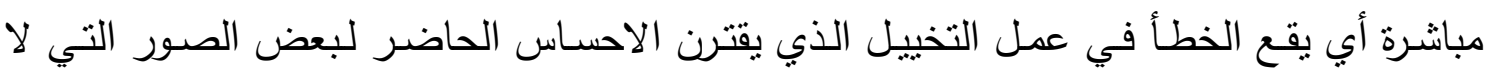

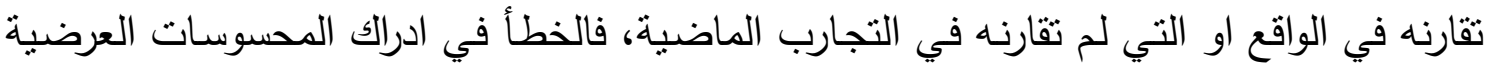
يقود الى التخييل والايهام الى الاحساس من تجارينا الماضية). (• ب) وعليه تبرز حقيقة الاثكال الايهامية كإحدى نتائج الادراك البصري المغلوط للفرد لذي يمكن من خلاله الكثف عن الاثكال

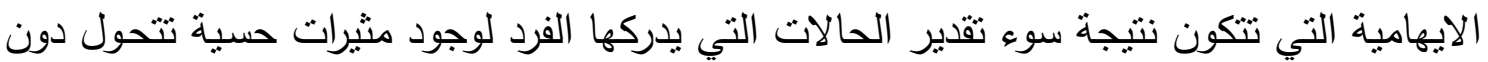
رؤيته للحقيقة.

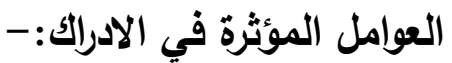

الادراك ينأثز بمجموعة من العوامل الاولى خارجية (موضوعية) تتعلق بالمنبهات او المثيرات

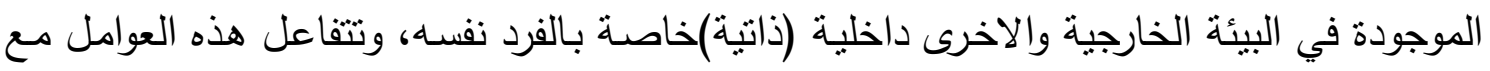

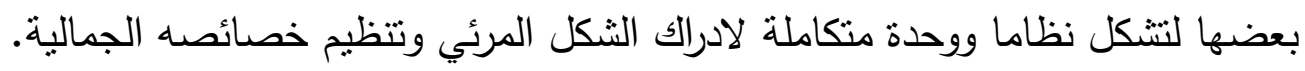

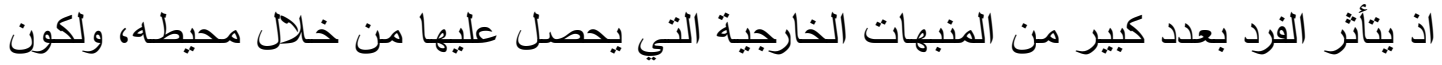

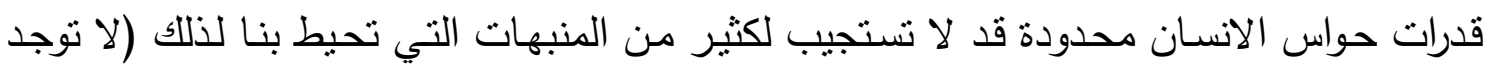
مطابقة تامة بين المنبهات الخارجية التي تؤثر في حواسنا وبين ما ندركه وانما يحدث فيها تغيير

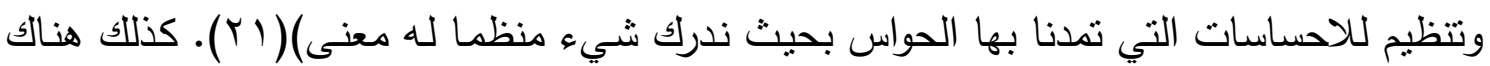


العديد من المنبهات التي يصعب على الفرد ان يدركها ويفهمها ويكون صورة واضحة عنها واعطاء

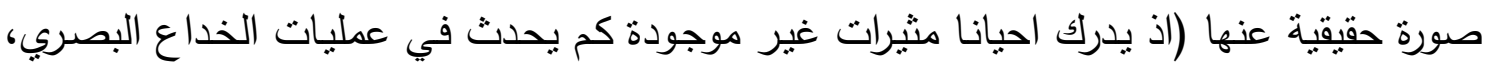

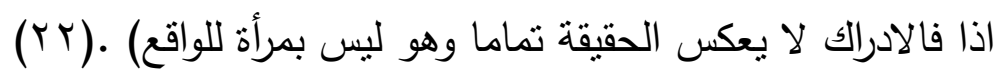

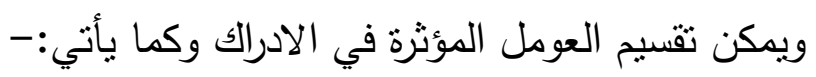

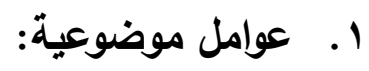

وتشـمل مجموعة العوامل المتمنلة في الخصائص الفيزيائة والكيميائية والكهربائية والاثـعاعية والحرارية والميكانيكية التي تتميز بها موضوعات العالم الخارجي من شكل ولون وحجم وحركة

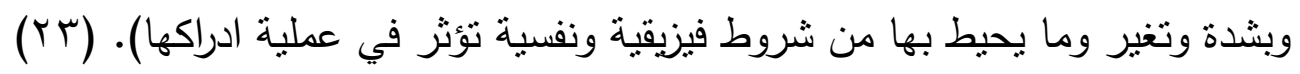

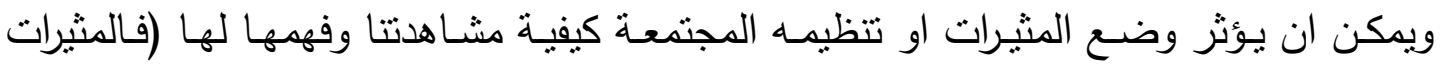

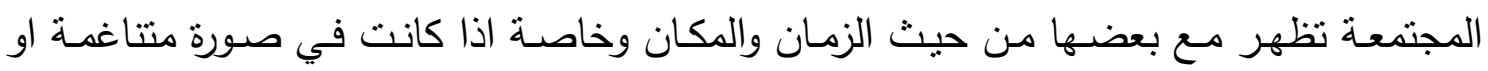
منظمة) ( ؟ Y). لذلك فالفنان يمنلك القدرة على جمع المؤثرات والمثيرات كافة الموجودة في الطبيعة

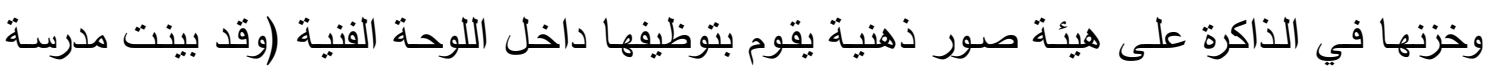

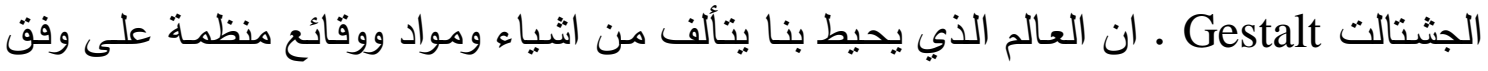
قوانين خاصة، نتشق من طبيعة هذه الاثثياء نفسها لا نتيجة نثاط عقلي او خبرات سابقة (فطرية)

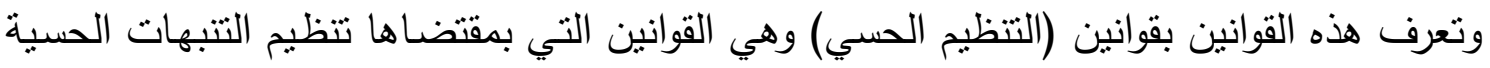

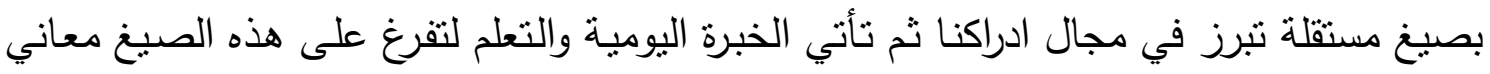
ود بلالات). (ro)

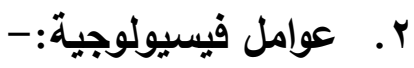

(تقوم العوامل الفيسيولوجية بدور اسـاس في عمليـة الادراك بـده مـن لحظـة تأثير المنبهات

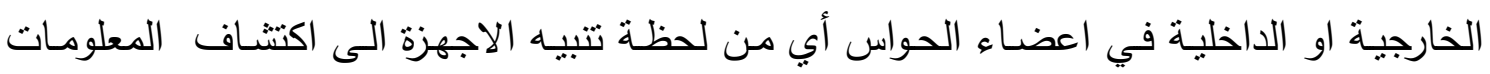

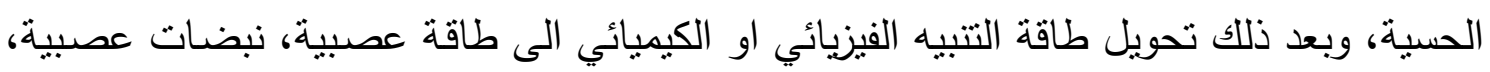

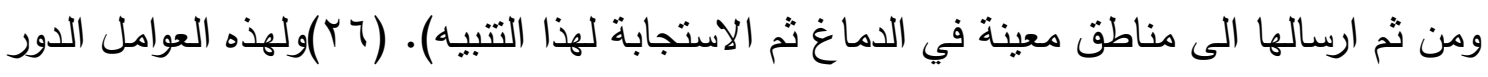
الرئيس في عمليـة ادراك الثكل المرئي وتقدير خصائصسه وتحديد حركته وشكله وحجمهـ وابراز جوانب مهمة في عملية تصوير الثنكل وانطباع معالمه على شبكة العين.

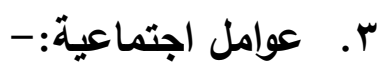

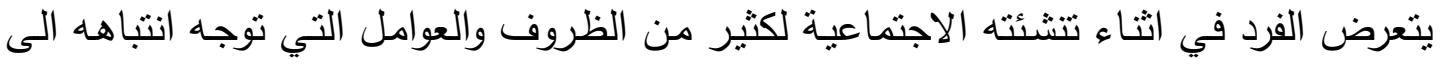

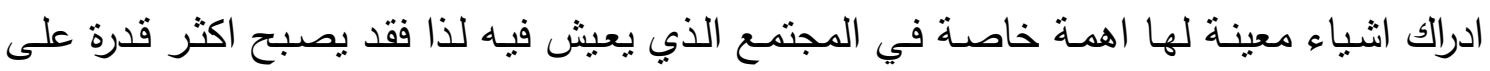

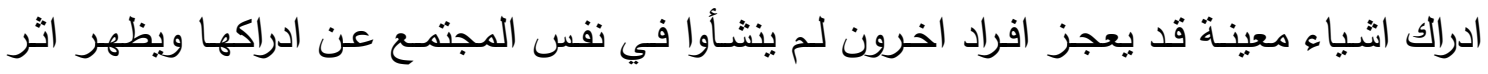


العوامل الاجتماعية في الادراك الحسي بما يسمى ظاهرة (الايحاء الاجتماعي) فنحن نميل الى ادراك الثيء بنفس الطريقة التي يدرك بها الاخرون) (rV).

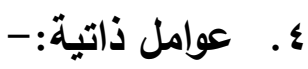

تتفاعل العوامل الموضوعية مع العوامل الذاتية في حدوث عملية الادراك وتؤثر هذه العوامل في انتباه الفرد الدركك ووعيه وذاكرته، فالادرالك هو عملية تفاعل بين نظامين هما:- نظام الموضوع لهوه

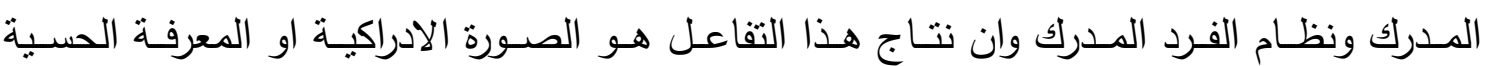

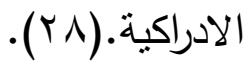

وهذا تبريره بالقول ان الفن عموما قد يكون نزعة فرديـة مضافا اليها مدركات البيئة المحيطة ومنبهاتها ويمكن ايجاز اهم العوامل الذاتية التي تؤثنز في عملية الادراك.

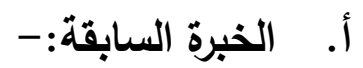
ان خبرة الفرد السابقة تمده بمعاني الاثشياء التي يدركها فنحن نؤول الاثشياء بحسب خبرتتا وهذا سيؤدي الى اختلافات في ادراك الثيء فالإدراك لا يقتصر على خصائص وصفات الاثشياء المانلة لألة

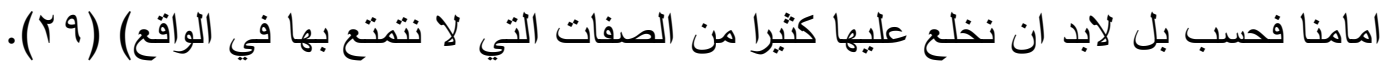

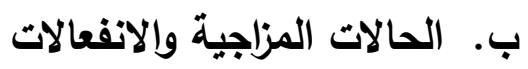
تؤثثر الحالة الانفعالية والمزاجية للفرد على ادراكه، فالإنسان الغاضب مثلا لا يرى في الثيء ما لإ

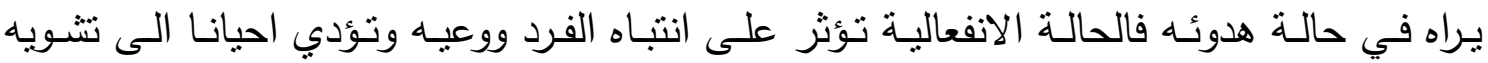

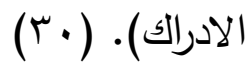

\section{ج. الميول والعواطف والانحيازيات:}

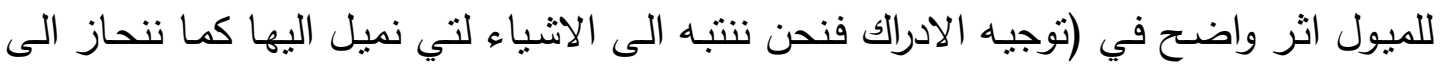
رؤية الحسنات في الاثشاء التي نحبها ونرى العيوب بشكل واضح في الاثشياء التي لا نميل اليها) .

$$
\text { د. الثقافة والعادات وإلتقاليد:- }
$$

تؤثز النقافة في شخصية الفرد وسلوكه فالتقافة تزود الفرد بالقيم والمعايير الاجتماعية وتكون اتجاهاته وميوله ليتمكن من تحديد معايير الصواب والخطأ وتحديد المعززات والمكافئات وتكون

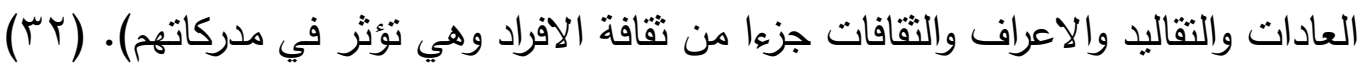

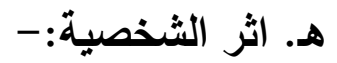
بينت العديـد مـن الدراسـات العلميـة (ان الادراك الفـرد يـرتبط بشخصـيته..وقد توصـلت هذهـ الدراسات الى وجود علاقة قوية بين ادرالك الفرد وعوامله الثخصية). (rr)

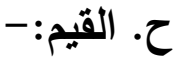


تقوم القيم والمعتقدات بدور مهم في تتظيم عملية الادراك (والقيم معايير اجتماعية ذات صبغة وجدانية قوية يجعلها الفرد موازين يوزن بها افعاله وسلوكه وهي اتجاهات نفسية مكتسبة تؤلف جانبا مهمـا من شخصية الفرد وتؤثر في سلوكه، وشعوره وادراكه وتتعدد القيم فمنها القيم الدينيـة او

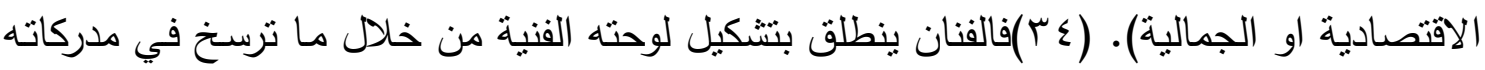
من قيم دينية مثلا واجتماعية عند معالجة موضوعات تتعلق بالعلاقات الانسانية.

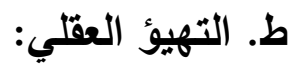

يؤدي الى حالة من الاستنفار العام بحيث تجعل الفرد في مستوى من الاستعداد لاستقبال مثيرات معينة ومعالجتها) · (ro) ومن خلال تلك العوامل الذاتية يستطيع الفنان من تحويل وتركيب وتحليل المعطيات وتفسيرها لغرض توظيفها من خلال اللوحة الفنبة. المبحث الثاني/ المتخيل - مفهومه، ووظائفه:

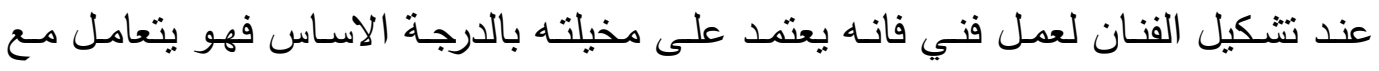

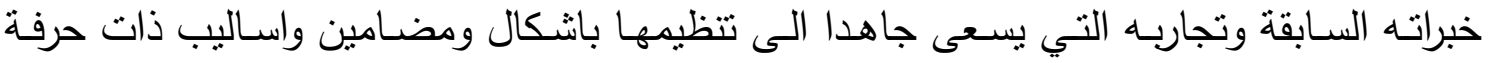
يضمن من خلالها ايصـال الافكار والمشـاعر والدلالات الموحيـة البعيدة عن الواقع في طريقة تجسيدها خلال اللوحة الفنية وقد يتفاعل الفنان مع المحيط الذي يتعايش معه وان يدرك ويستذكر تفاصيل مـا يحبط بـه من خـال الاحساس الواعي الذي يعبر عن حالة شعورية يعيشـها الفنان

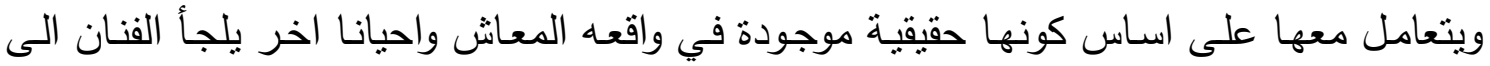

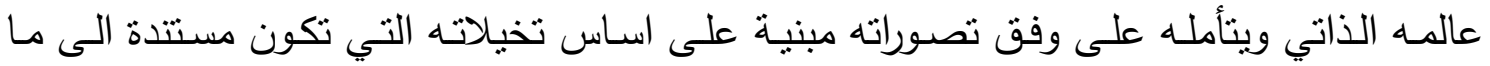
يمتلكه من خزين صوري ومعرفي بستذكرها ويتعايش معها في حينها بالاعتماد على ما يمليه عليه الثـعور والوعي بالمدرك لهذه الافكار والتصـورات فالدفـاهيم الخيال-المتخيل-التخيل-التخييل والتصور والتي من خلالها يقدم الفنان صور فنية منجزة بكل غرائبيتها وفنتازيتها وايغالها في عمق النفس البشرية وبكل عوالهها اذ يعدد الفنان الى تكوين واقع افتراضي تتجسد فيه تللك الصور على وفق رؤيـة ابداعية وفلسفية معبرة حسب طبيعة الحدث المتخيل كل وفق تمظهره انما تعد حالة يتعـايش معهـا الفنان وان يقف ازاء كل منها باسلوب ونمط يتضـمن امكانيـة ايصـال الدلالات

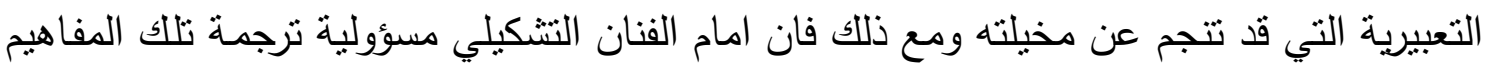
الى منجز مرئي الذي يشكل عبر رؤية في صياغة الادوات الفنيـة التي تسهم في بلورة وبنـاء

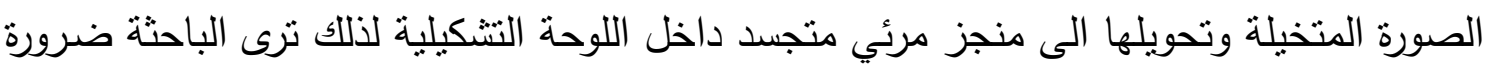
دراسة هذه الدفاهيم بشكل مفصل على النحو الاتي:-

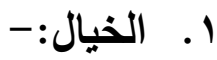


يعد الخيال احد العناصر التي يعتمد عليها الفنان في بناء عالم من الصور المتخيلة وتجسدها

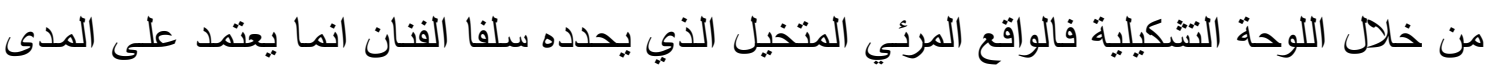

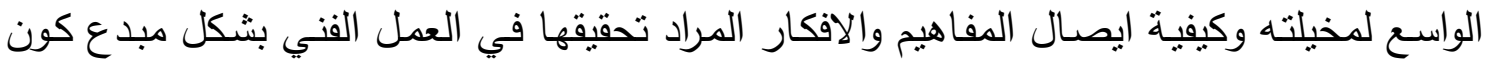
الخيال هو الملكة المولدة للصور الحسية المستلمة بواسطة اعضاء الحس والتي يتأسس خلالها

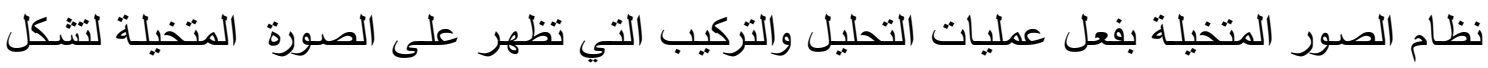

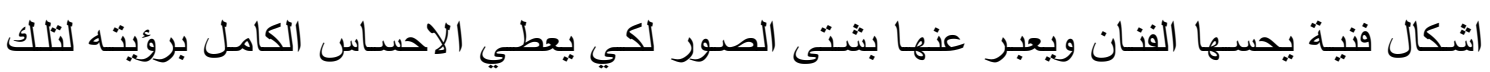
الصور وتجسيدها بكل ما تحمله من غرائبية

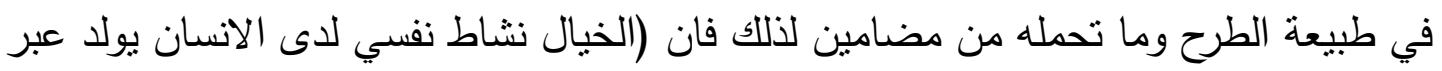

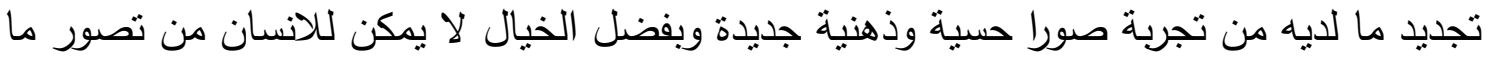

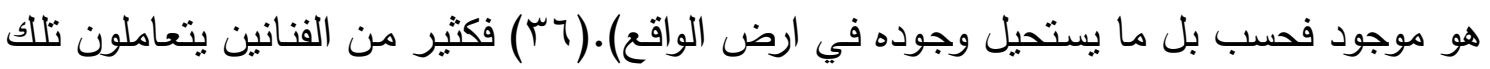

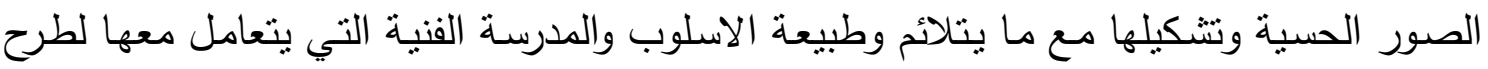
افكاره ورؤاه الفنية وتحقيق هدفه في النهاية (فالخيال هو نتاج عملية حسية وعقلية والاختراع احد

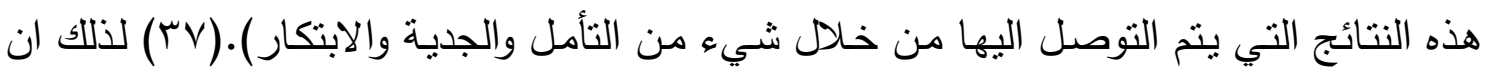

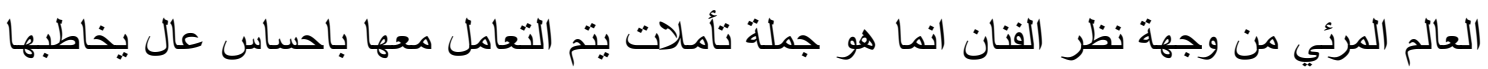

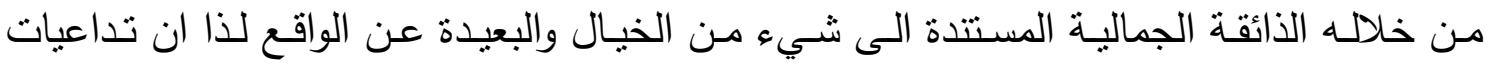

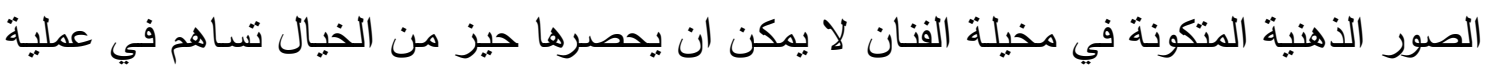

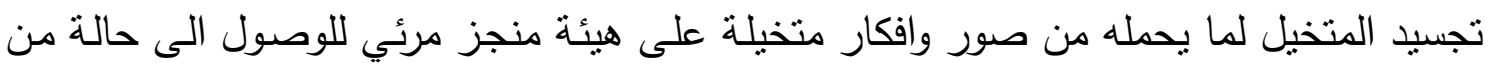

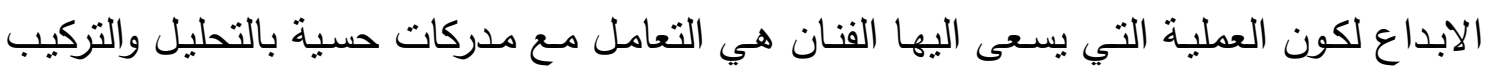

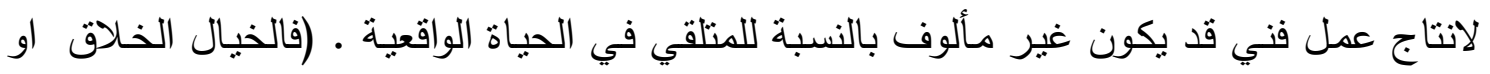
المبنكر هو نوع من العمليات تتخطى الظواهر والمظاهر وهو بالنتيجة عملية بناء وخلق لظواهر

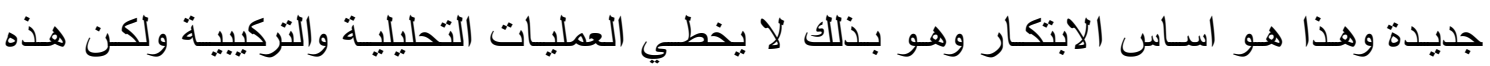

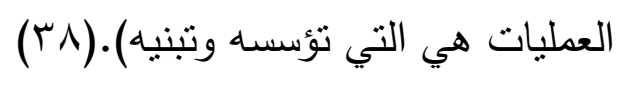

لان الافكار تؤسس اثكالا معينة يتم من خلالها ايصال اشكال مرئية بمواصفات جمالية تحمل فئل

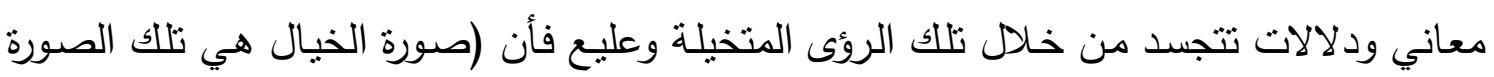
التركيبة السحرية التي تكثف عن ذاته في خلق القرارات او التوفيق بين الصفات المتضـادة او اونان المتعارضة بين الاحاسيس بالجدية والرؤى المباشرة). (9 (ب) .

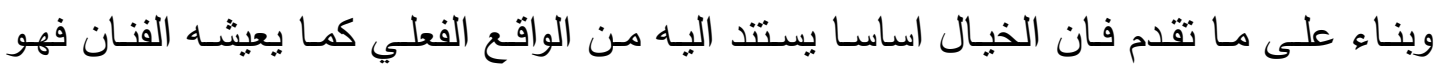

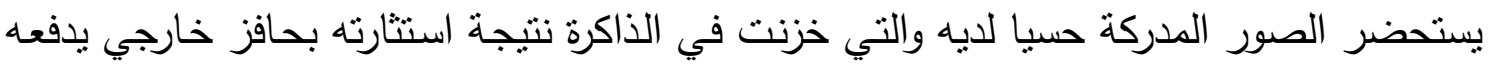

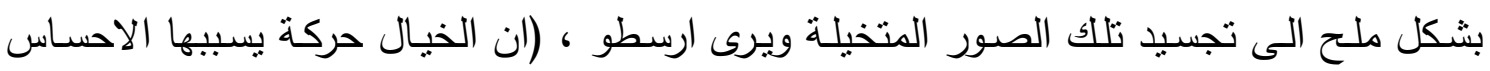


بحيث لا يتأتى للخيال ان يوجد بدونهـ أي الاحسـاس).(• ؛ ) واذا مـا حصل وان اصـاب الادراك

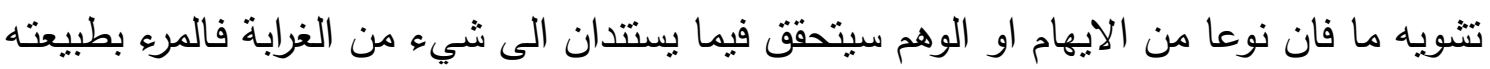

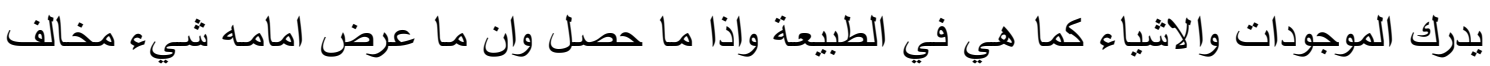

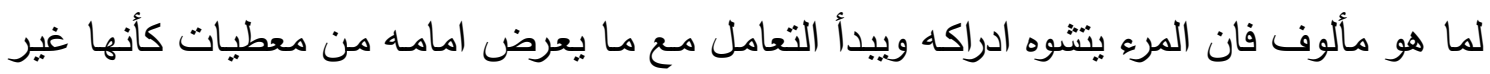

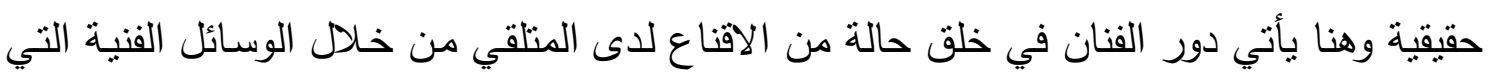

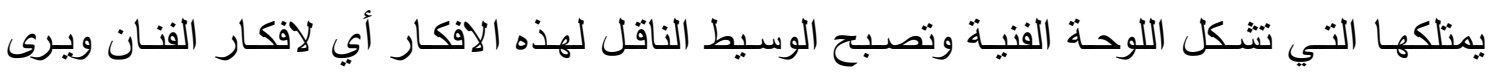
(كولدرج) (ان الوهم والخيال الذي يعمل بمقتضاه النشاط الاول على خلق عمل فني تكون عناصره واضحة المعالم وغير محدة رغم كونها متجمعة في حين ان الثاني يبتكر عملا ترنبط عناصره

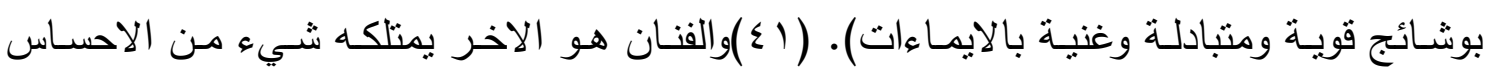

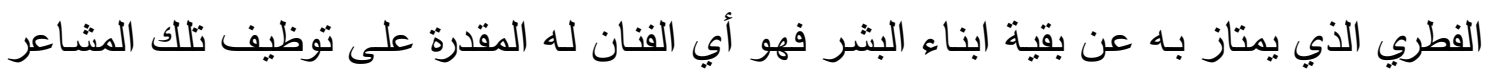

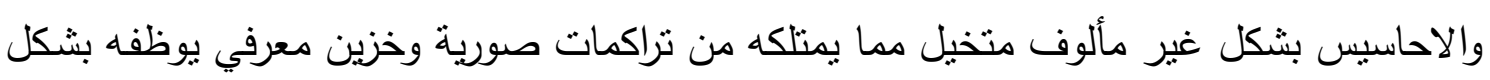

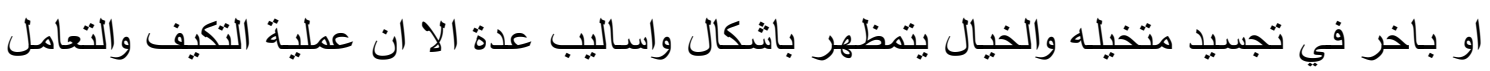

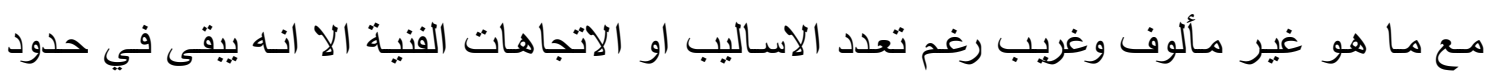

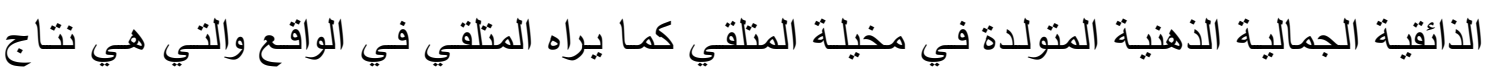

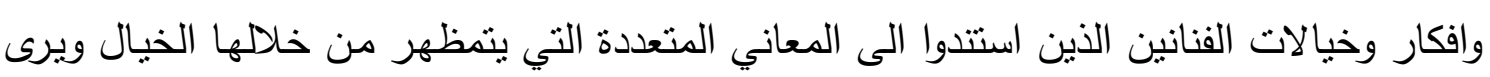

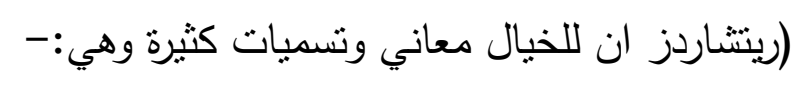

1. . توليد صورا واضحة وخاصة الصور المرئية، وهذا اكثر المعاني شيوعا واقلها اهية.

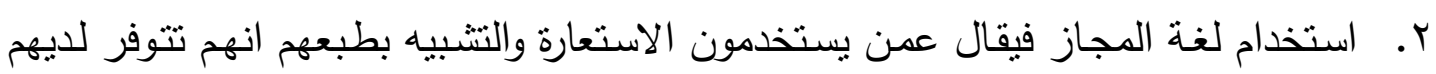

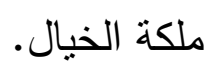

r. تصوير الحالات الذهنية للغير عن طريق المشاركة الوجدانية ولا سيما حالات العاطفة وهذا الضرب من الخيال ضروري لتحقيق عملية التخييل.

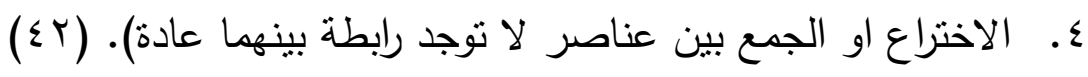

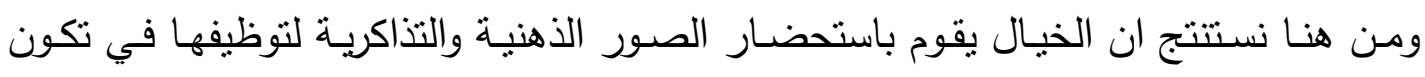
منجز مرئي (اللوحة) تتفاعل فيها العناصر والادوات المجسدة للعمل الفني لخلق عوالم متخيلة وقد بلند تكون مماثلـة للواقع المعاش او بعيدة كل البعد عنه وفق المدارس والاتجاهات الفنيـة التي تمثل

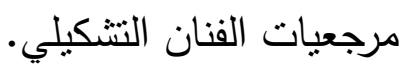

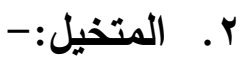

يعرف كولودرج المخيلة (بانها القوة التي تكثف عن نفسها في اتزان الخصائص المتعارضة او

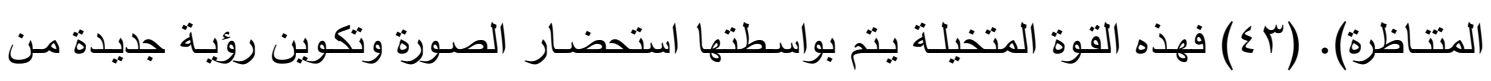


خلال تركيب تلاك الصور للوصول الى حالة الابداع ولذلك نجد ان الفنانين بما يمنلكونه من خزين معرفي وتجربة سابقة في مجال عملهم يسعون دائما الى ايجاد افضل السبل لتكوين منجز مرئي يتسم بالغرابة وسعة الخيال (حيث بمكن ان يكون المبدع او المبتكر هو ذلتك الذي استطاع بواد بواسطة

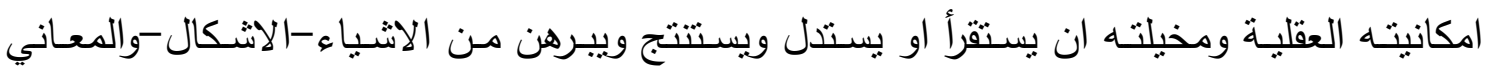
ومستوى المخيلة المتجلية في مادة عملية الفن وان ييني ويركب بعد عمليات التحليل مظـاهر

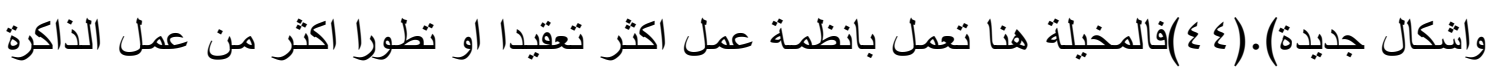

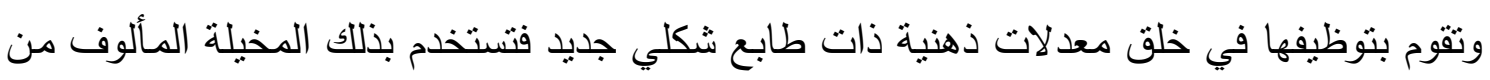

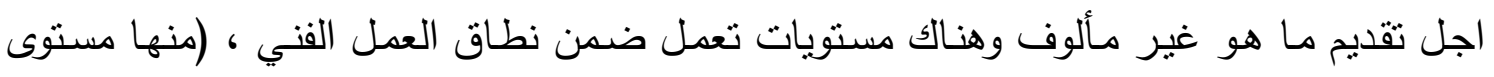

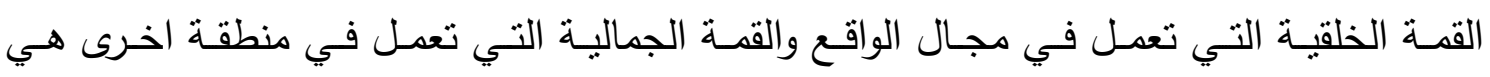

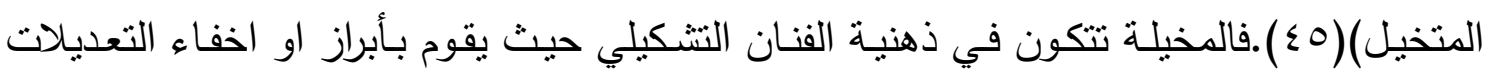
وتحويرها باسلوب ينسجم وامكانبة استيعاب المتلقي لما يطرح امامه من عوالم متخيلة بشكل مغاير

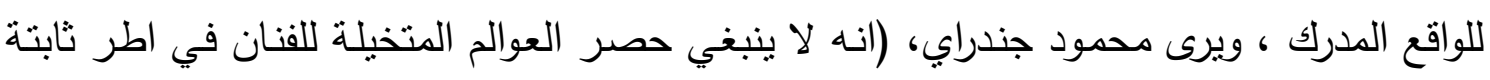

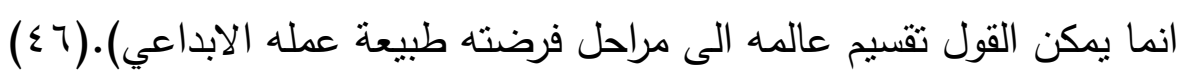

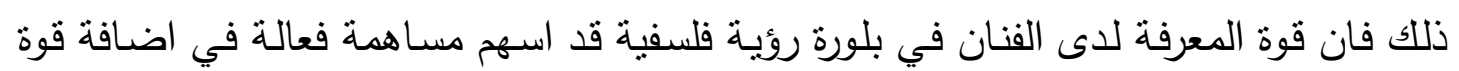

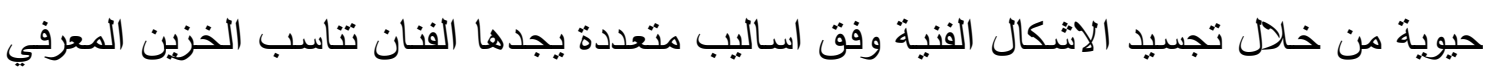
لايه عند بناء اللوحة الفنية بشكل يتلاءم مع الخصائص الاسلوبية للمدارس الفنية التي يستتد اليها

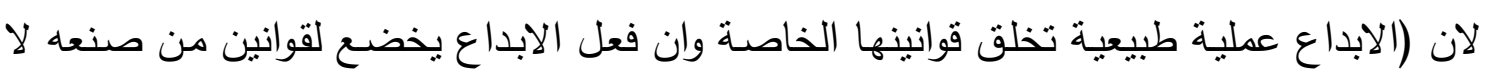

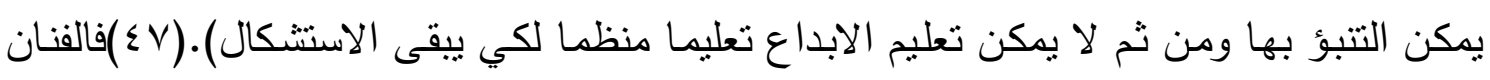

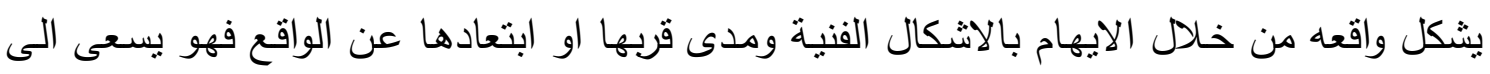
تجسيد المتخيل داخل المنجز المرئي من اجل الوصول الى تحلى تحقيق هدفه.

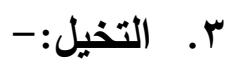

الفنانون يتأملون الواقع المدرك فتتكون لديهم صورا ذهنية عن ذلك الواقع وتلك الصور قد تتسم

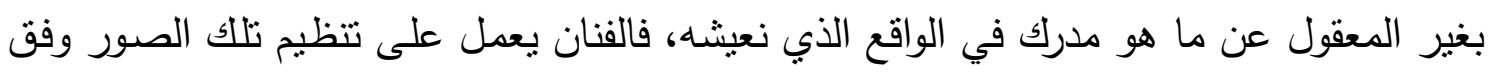

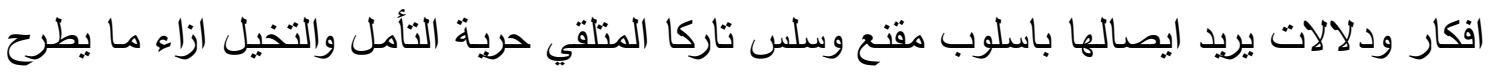

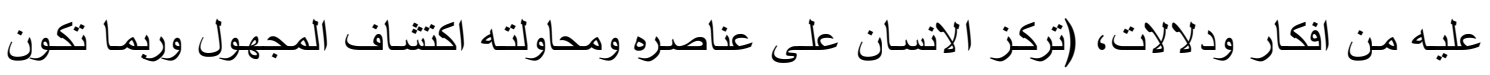
عناصره مجردة ولكن في تنكيل جديد).(1) ).

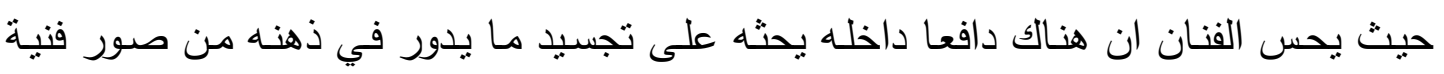

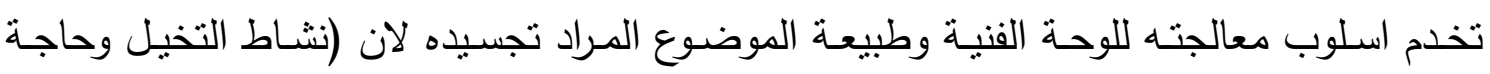

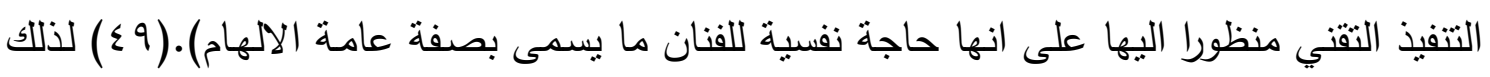


يمكن اعتبار التخيل نشاط ابداعي يتميز به الفنان والمادة التي تغذي هذا النشاط هي الطبيعة او

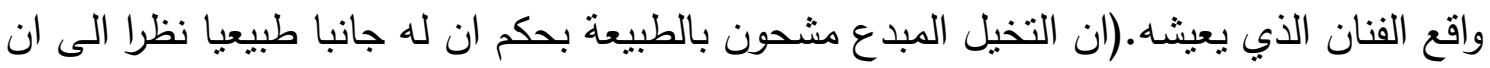

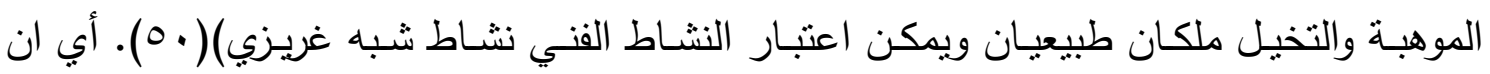

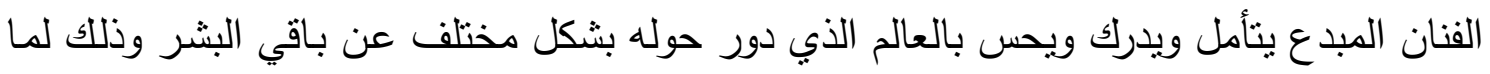

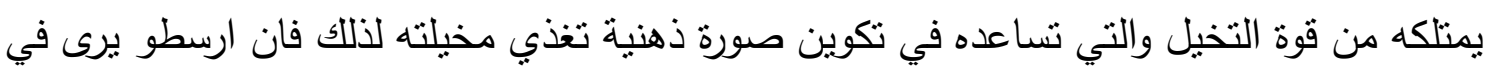

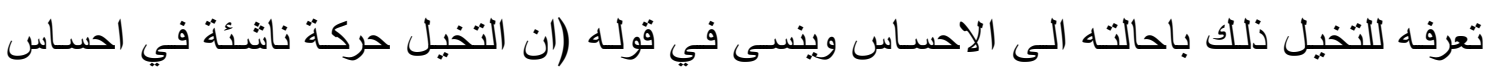

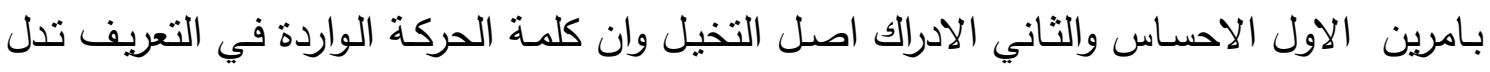
من قريب على ان التخيل عملية دينامية).( (10) وقد حدد (ابن سينا) مجموعة مضامين للتخيل هي:-

ا. ـ ان الكـلام المخيـل موجـه الـى مخاطبـة الغيـر فتخيـل الثـعري نظـري التصـيق الجـلي الخطابي.

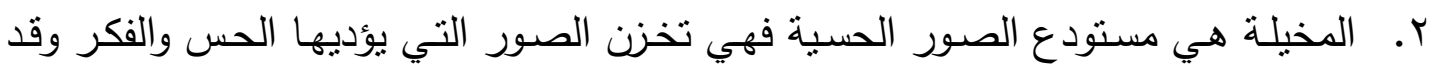

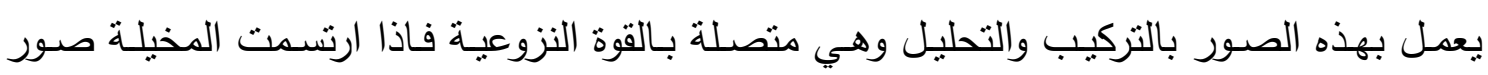
محبوبة او مكروهة تتشط بالقوة النزوعية التي طلبها او الهروب منها.

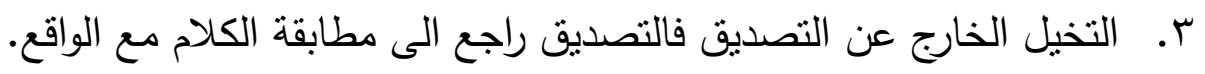

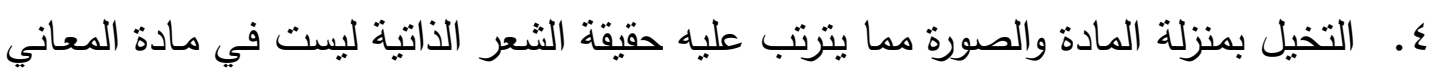
بل في صورتها.(Or) وعليه ان معاني التخيل عند (ابن سينا) تستحضر الصور الذهنية والذاكرة للوصول الى المخيلة

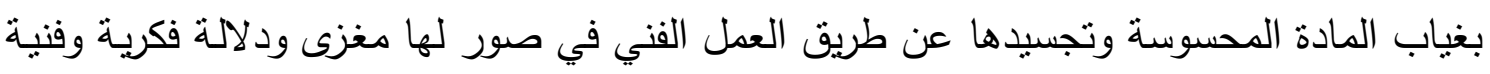

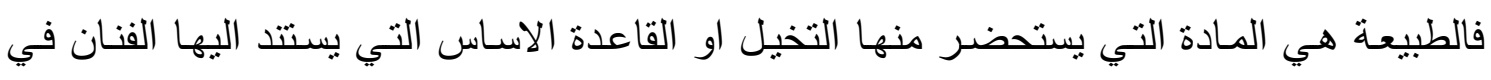
تكوين صور التخيل ، فصور التخيل تحاكي الواقع وان ادخلت عليها بعض العطليات التحليلية التركيبية فالتخيل يمكن ان يكون الاساس التي تتطلق منه عمليات وخطوات التخيل. التخييل:ورد عن لسان العرب لـ(ابن منظور) (بيين لهم من سحرهم انها تسعى أي شبه وخيل له انه كذا على ما لم يسمى فاعله من التخييل والوهم )

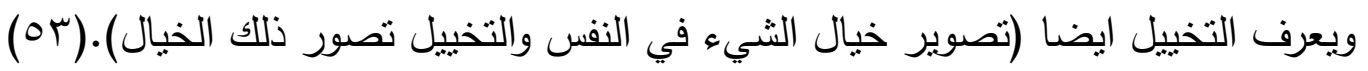

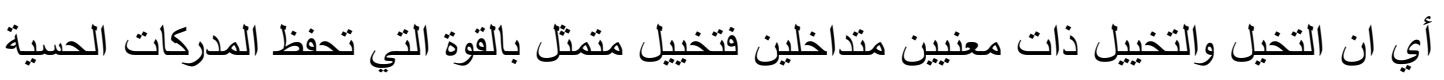

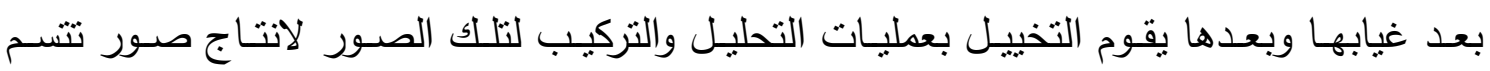


بالاصالة والابتكار لذا فالتخييل (يتميز عن قوة الافكار وحيويتها واستنثاءها وكذلك الصور التي

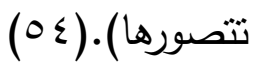
ويتجسد العمل الفني الغرائبي عبر تكوين صور تتميز بخصوصيتها وغرائبة شكاها ليتم تجسيد عبر منجز مرئي يتثكل من خلاله قوة الصور الحسية المعبرة ، وتعرف هذه القوة أبي (قوة التخييل هي اللحظات العامـة التي ترتبط بعطلية التخييل، والتخييل مولود مـع الانسان لكن يقوى وينستج

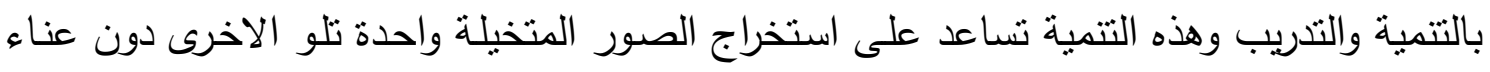

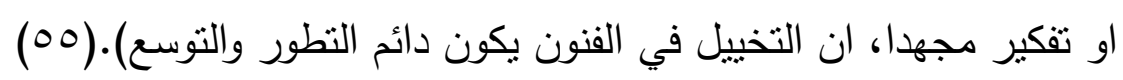

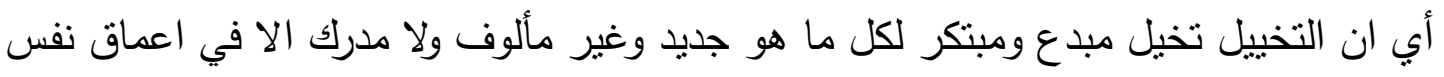

ان تصور الثكل المرئي واعطائه ابعادا وهيئات مختلفة يشكلان حسب طبيعة ادراك الثكل

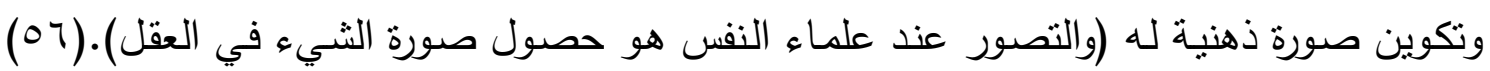

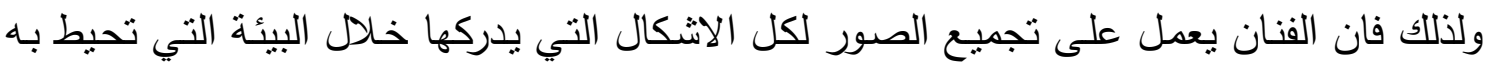

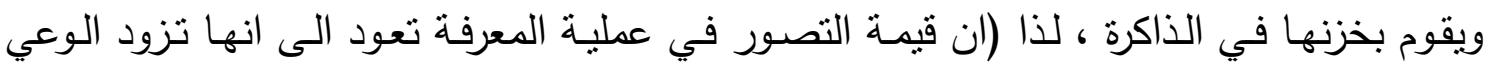

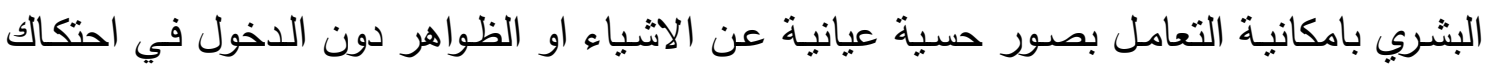

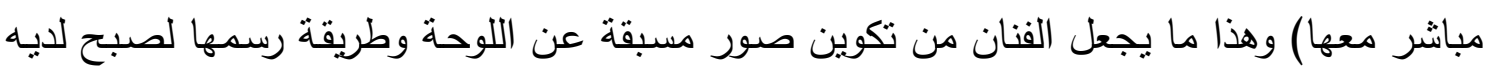

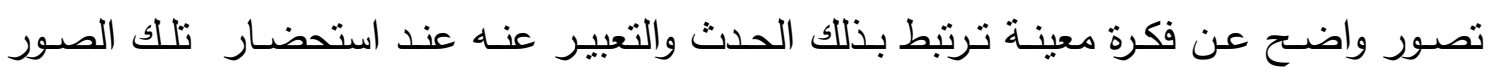

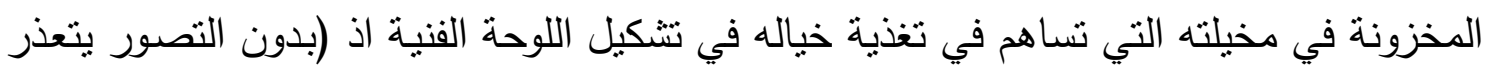

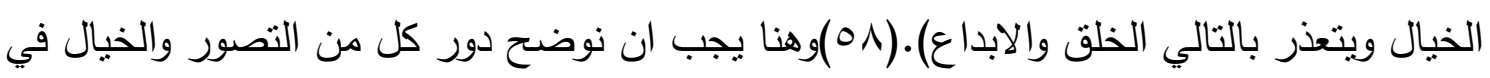

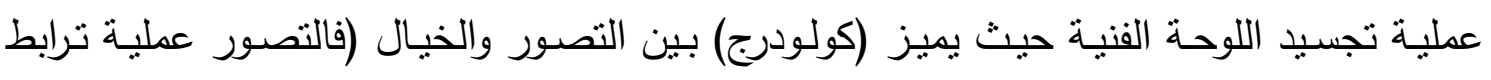

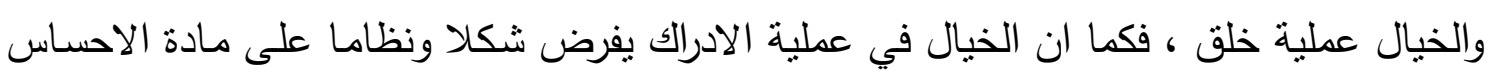

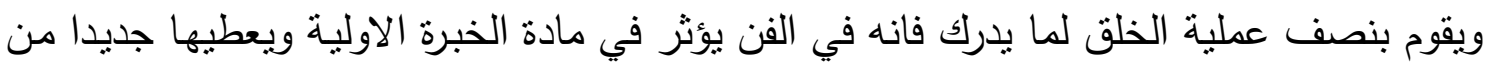

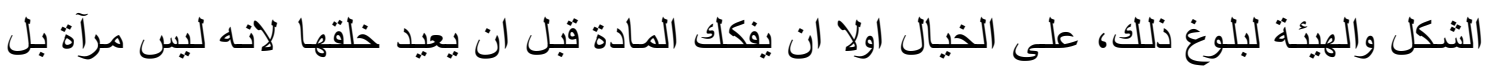

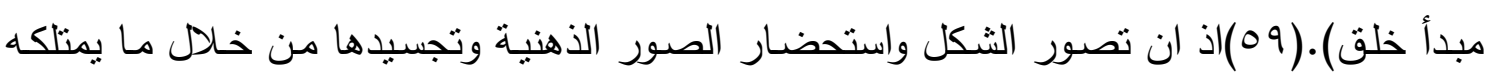
الفنان من خبال بضفيه على الثكل الجديد المنصور وتجسيده خلاد اللوحة الفنية لذلك فاننا نقول

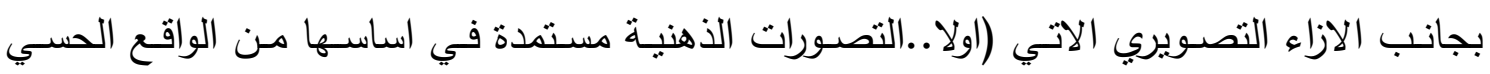

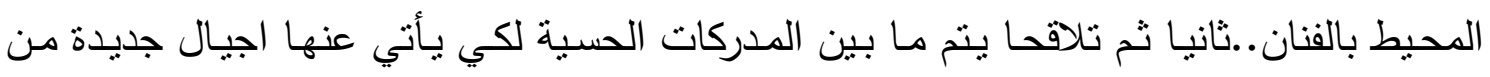

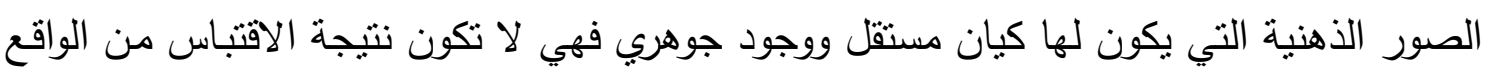

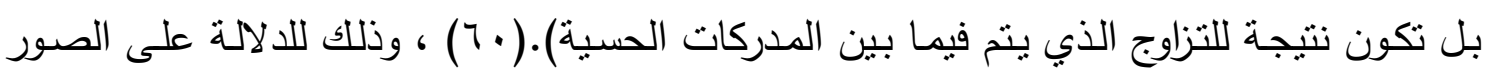


الحسية التي يدركها الفنان لمجمل صفات الثخصيات والاشكال المرئية التي يعيش معها الفنان ويتفاعل من اجل تكوين صورا ذهنية على الاثكال البشرية وصفاتهم والوانهم كافة. المبحث الثالث/ آلية اشتخال المتخيل:

للفنان القدرة على استحضار الصورة التخييلية من خلال التخييل فالتخييل (هو القدرة على خلق الصور الحسية او فكرية جديدة في الوعي الانساني على اساس تحويل الواقع المدرك في لحظات معينة ويكتسب الانسان مقدرة التخيل عن طريق العمل الذي لا يكون بدون التخيل مجديا ومثمرا).

فالفنان له القدرة على التخييل من خلال توظيف امكانيته الفنية المرافقة للكم الهائل من الخبرات والمعلومات التي يحتويها الدماغ الذي يسعى الى طرح كل المعلومات والصسور المخزونـة التي تساعد الفنان في نتككيل تصوره الذي اثار اهتمامه في الكثف عن كن كوامن الابداع في الثنكل المتخيل. وعليه فالمتخيل يعمل على محورين التخيل والتخييل (هو النشاط الحر فيما يشبه احلام اليقظة التي تتتقل من موضوع الى اخر على نحو حر تماما من دون التزام بروابط او نظام كما في

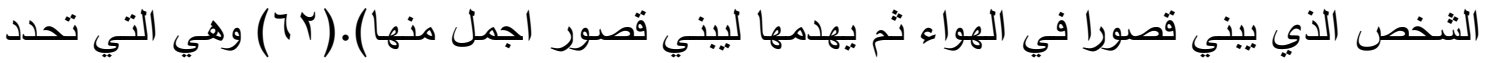

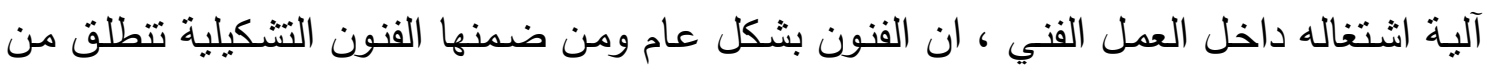
افكار ورؤى متخيلة لدى الفنان والتي تترجم وتتمثل بصور الاثياء الغائبة وكأنها موجودة ونعيش لحظاتها ونتصور تفاصيلها واحيانا اخرى نتخيل صورا وتفاصيلها اثشياء وهذا بفضل نشاط التخيل اذ انه (نشاط حر لكنه موجه على نحو غير مباشر في الوقت نفسه نحو موضوع معين يكون بؤرة لنشاط خاص بالتفكير البشري، تتجمع حولها كل ما يذكرها ويدعهما ويعمقها من الصور والذكريات والانطباعات والانفعالات وهو نشاط يقوم به الفنان والمبدع للخيال او المتلقي له وغالبا ما يرتبط

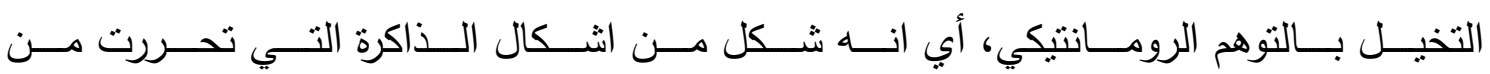
روابطها).(rآ)وتتمظهر قوة التخييل باثكال صورية وحسب رأي (هربرت ريد) نجد انه يؤكد على التى الصورة التذكرية والتخيلية والصورة التكوينية وذلك لان التخيل لـه (القدرة على ربط الصور فيما بينها التذكارية وذللك لاقامة ترابطات بين تلك الصور سواء في عملية التقكير ام في عملية الثعور الوجداني).(؟ T)وهناك نمط اخر من الصور التي تتمظهر بها فهي اما ان تكون صورا ناتجة عن

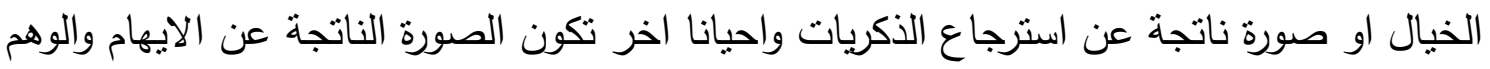
والفنان يسعى لاستدعاء مـا تختزن ذكرياته محاولا مقرانتها بالواقع من جهة وتطويعها في بوتقة

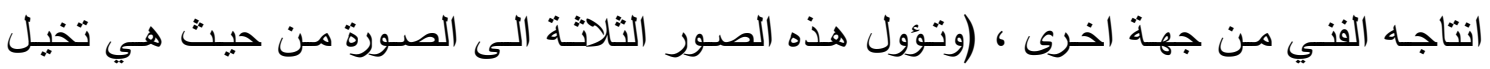
(الصـورة- الخيـال) والصـورة باعتبارهـا تذكيرا (الصـورة-الذاكرة) واخيرا الصـورة بوصفها توهمـا 
(الصورة- الوهم) وكل صورة على هذا النحو افق تتجلى في سمته بحيث لا تختلط افاق التجلي

ويمر المتخيل في المرحلة التالية حيث الولوج في تغييرات وتحليلات ما هو متخيل من صور

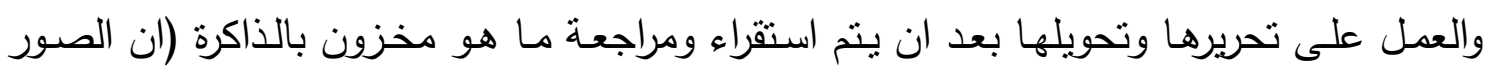

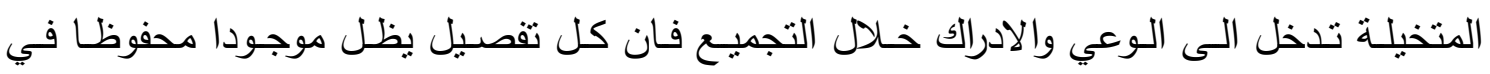
الاحساسات والذاكرة كجزء من الكل سواء كانت صورا صوتية بعض من تتابع ايقاعي غنائي او

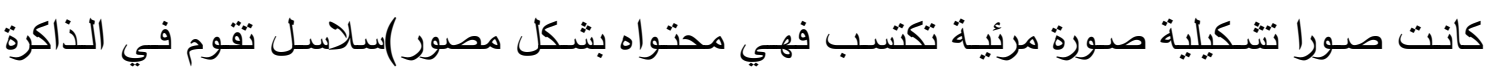

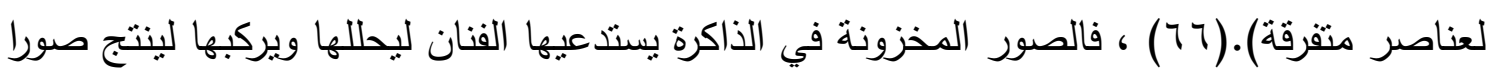

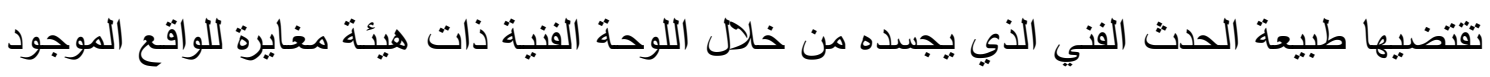
فيه، قد يستعين الفنان بعالمه الذاتي لتصور ونتكيل العناصر الفنية داخل اللوحة التتكيلية. انواع المتخيل:

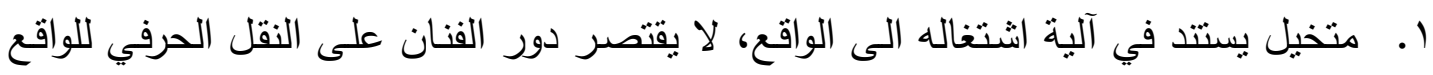

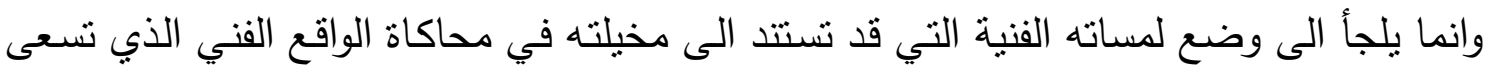

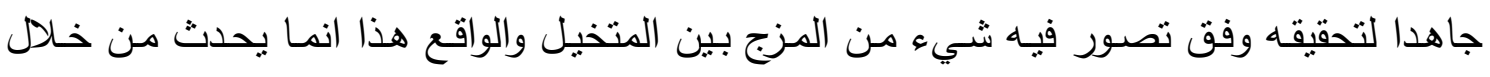

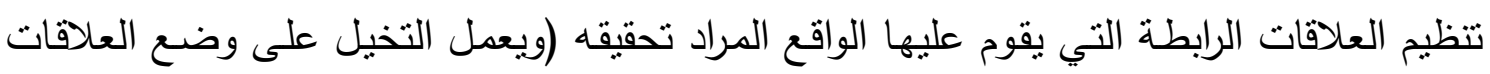
الموجودة بين الحقائق واقعيا في علاقات جديدة).(TV)

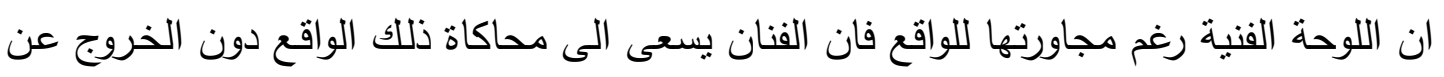

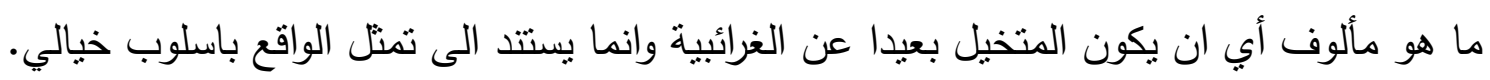

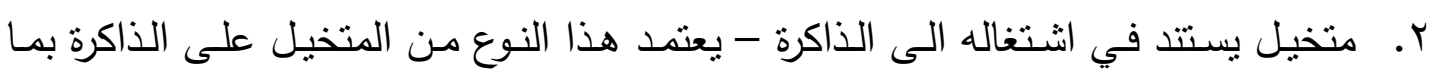

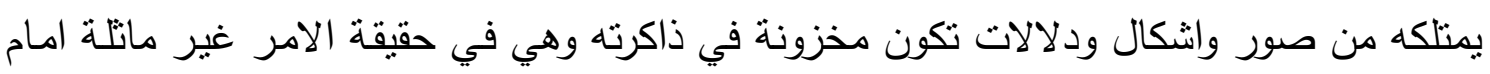

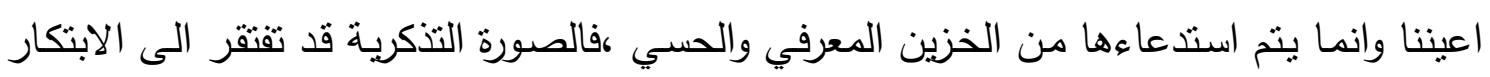

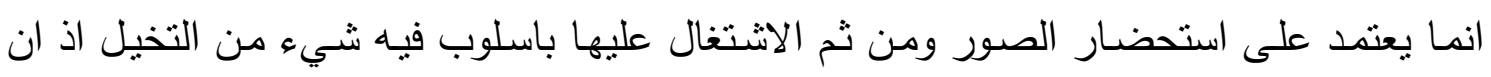

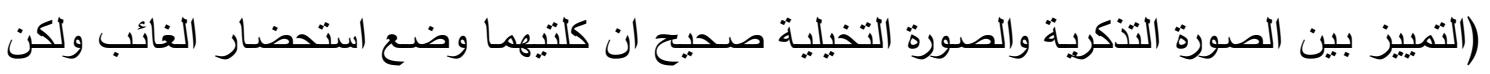

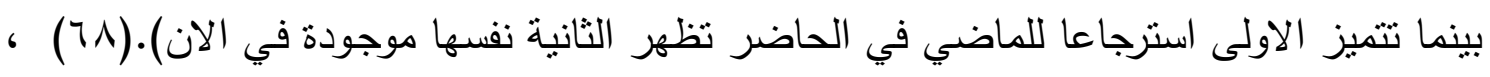

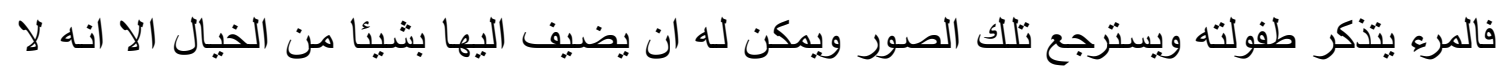

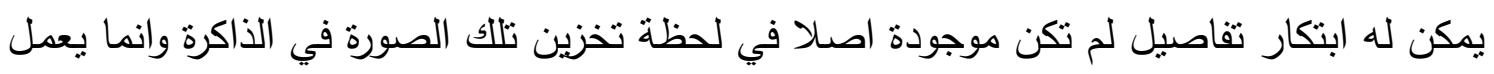

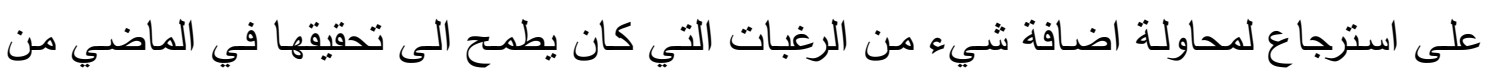
خلال الصور المتخيلة. 
r. المتخيل الذي تعمل اليات اشتغاله على الطبيعة- يعتمد الفنان في هذا النوع من المتخيل

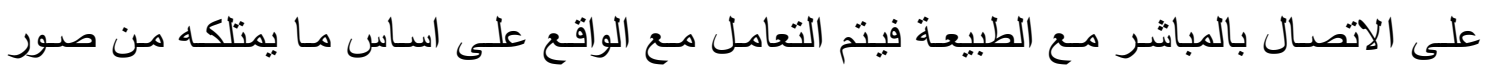

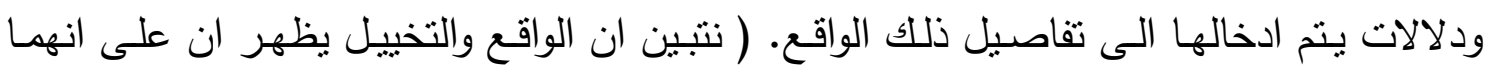

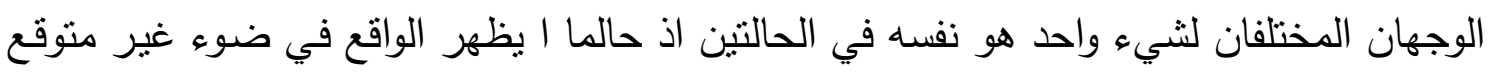

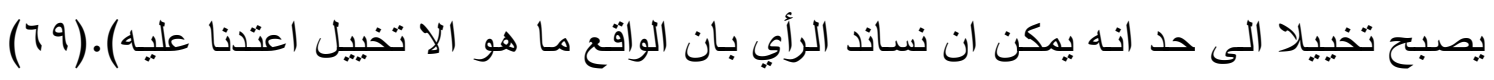

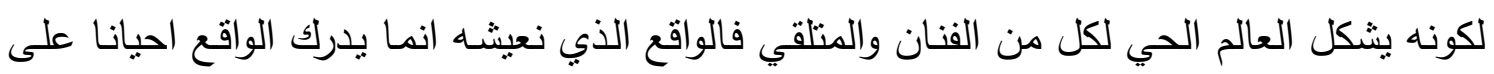

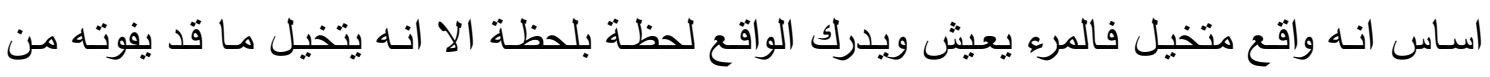
لحظات وما قد تأتي اليه لاحقا رغم كونه يعيش ذلك الواقع بكل احساساته ومدركاته.

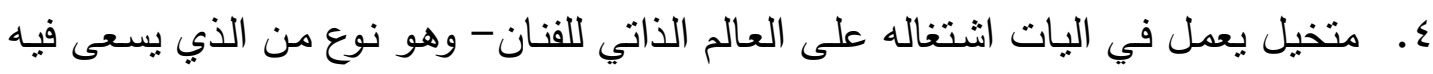
الى الاعتماد على تخييل الصورة المتولدة في ذهنه وقد لا تخلو من الغرابة في تصورات ذلكي الكئل الفنان

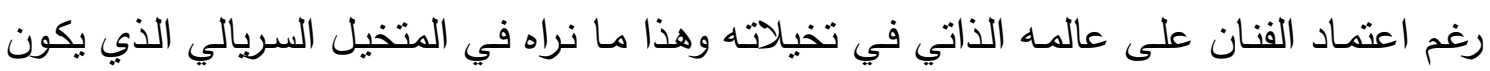

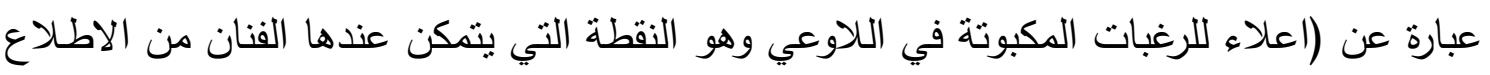

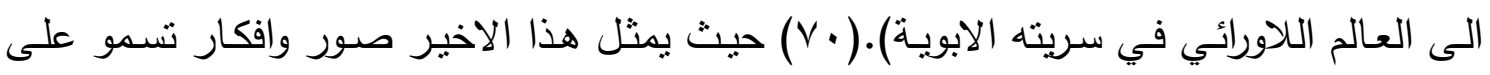

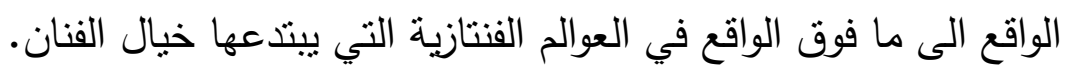

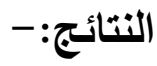

من خلال دراسة البحث الحالي توصلت الباحثة الى عدد من النتائج لتحقيق هدف البحث كما

ا ـ ان المتخيل يكون مستوحاة من الواقع موضوعه الجمالي ولكن يعاد صياغته من خلال عمليات التحليل والتركيب بحيث يقدم عمل فني يمكن ادراكه.

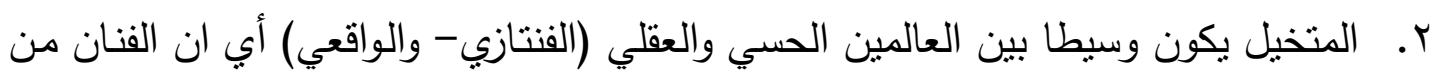
خلال تأمله للطبيعة يستطيع ان ينتج ويبدع فنا جميلا يتذوقه المتلقي.

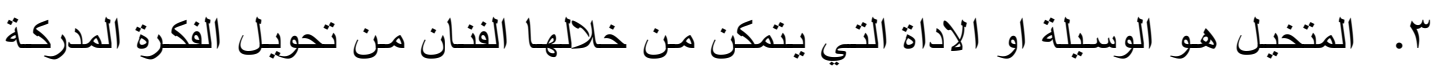

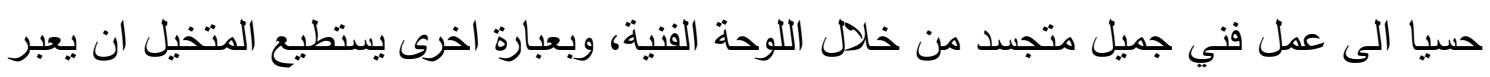
عن كمال وجمال هذه اللوحة المدركة.

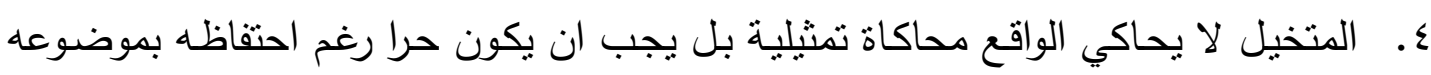
الروحي ومن ثم لا يفرض قيودا او حدودا للقدرة الابداعية للفنان.

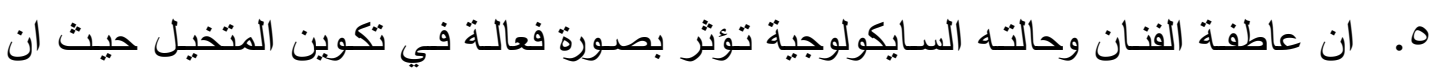
العاطفة تهب الحس تماسكه ووحدته فالحدس يكون مرنبطا بالخيال. 
7. المتخيل يكون رمزيا وذلك لان الفنان ينتج عملا فنيا مبدعا وهذا الابداع الفني المتخيل يعد تحولات رمزية كتفاعل منطقي للخبرة الباطنة والرمز هو نطبيق للخبرة الباطنية المستمدة من الواقع وعليه فالفن رمز متخيل والخيال هو الذي يضفي على الاشكال الفنية عناصر جديدة ترفعنا الى تذوقها. V. . يكون المتخيل مثاليا يرتبط بعالم الروح وعالم الممكنات غير المدركة في الواقع. 


\section{الهوامش والمصادر:}

1. Mcmahon, F, Psychology,the Hybrid Seience,prentice 3ed-Hall Inc,New Jersey,1978.p.609.

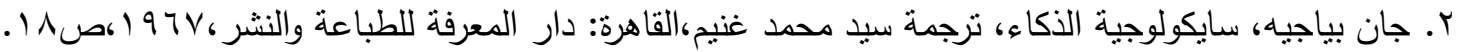

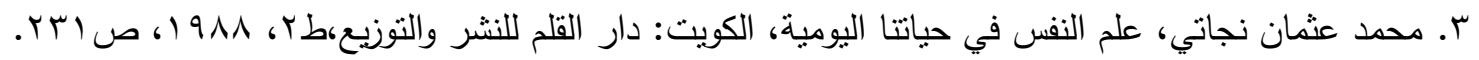

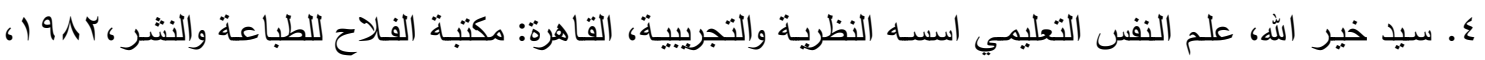
صמrtron

ه. علي محمد علي الجرجاني، التعريفات، تحقيق ابراهيم الايباري ،بيروت:دار الكتاب العربي، طا،صوجس.

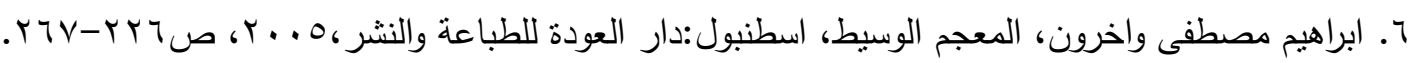

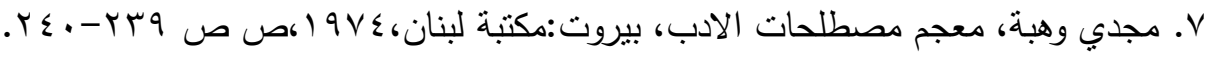
A. هربرت ريد، تربية الذوق الفني كترجمة كيوسف ميخائيل اسعد، بيروت: دار النهضة العربية، دار الاتحاد العربي

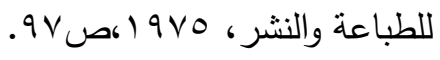

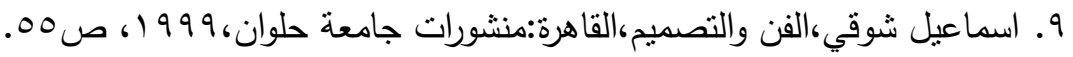
10. Lam.William.M.C.Perception and lighting as form givers for architectare. Christopher Hugh Rigmana,(Editon) Mc Graw-Hillbook Company Inc, St.louismichigan-USA, 1977,P,30.

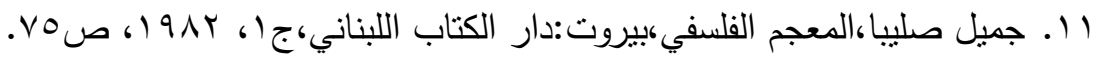

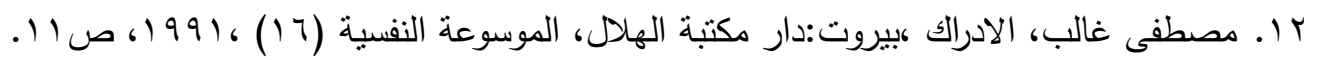

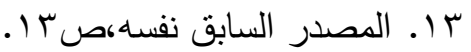

ـ ا. علي منصور وزميله، سايكولوجية الادراك،دمشق منشورات جامعة دمشق، 997 19، صلrV.

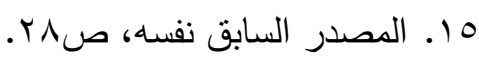

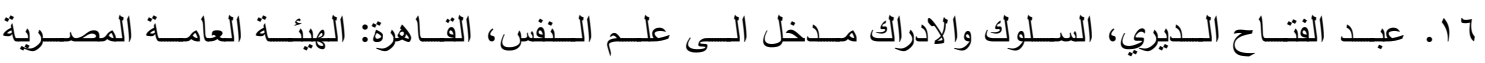

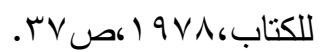
V IV

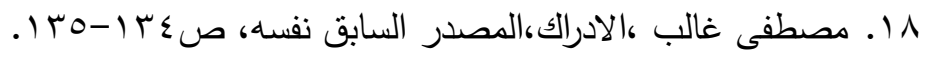

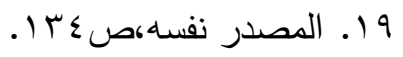

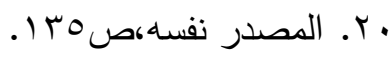

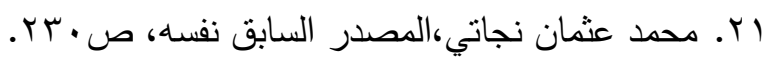

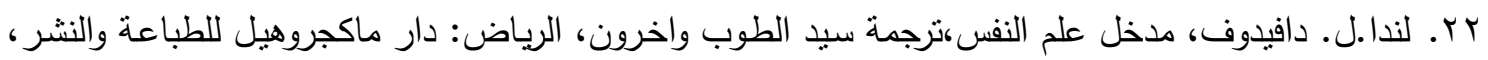

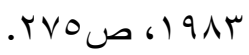

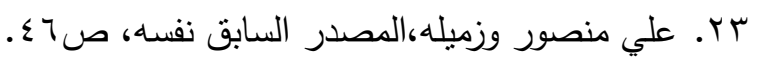
ع ז. ارنوف وينتج، مقدمة في علم النفس، ترجمة عادل عز الدين الاشول واخرون،القاهرة: دار ماكجوهيل للطباعة

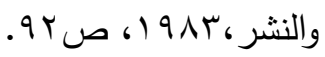
هr. احمد عزت راجح، اصول علم النفس،صر : المكتب المصري الحديث للطباعة والنشر، طا، الاسكندرية، 
דr.

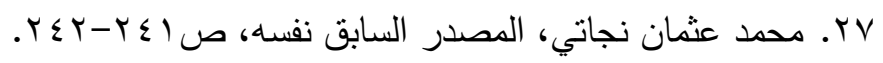

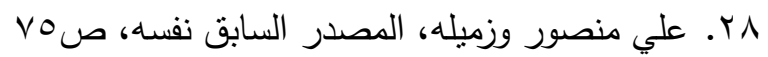

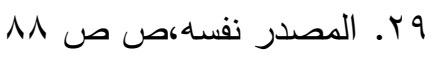
• r. مها عبد الحميد جواد العاني، اثر بعض المتغيرات في الادراك ،جامعة بغداد، كلية الاداب، اطروحة دكتوراه غير منشورة، 999 19، .0.

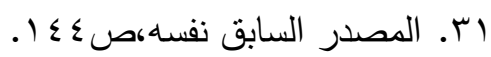

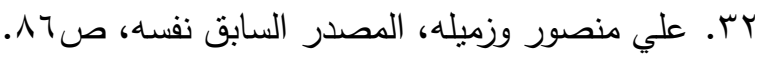

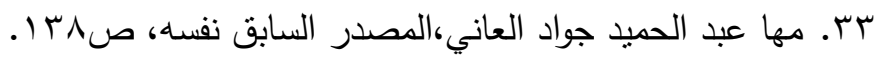

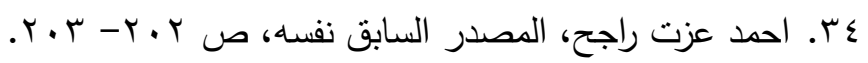

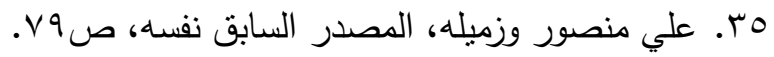

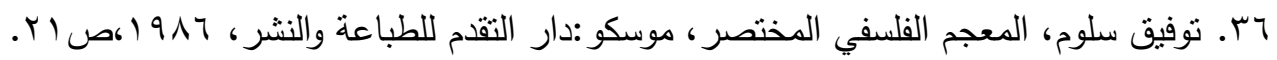

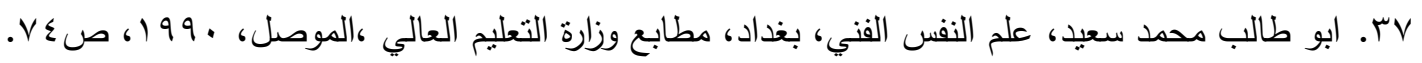
^ז. نجم عبد حيدر،التحليل والتركيب في العمل الفني التتكيلي،اطروحة دكتوراه غير منشورة،جامعة بغداد،كلية

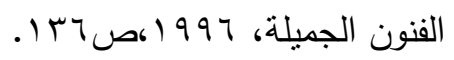

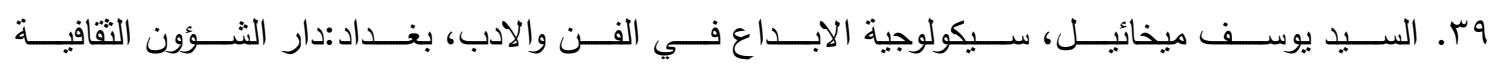

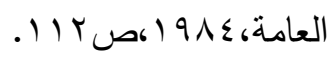
• ــ شاكر عبد الحميد، العملية الابداعية في فن التصوير، الكويت: سلسلة عالم المعرفة، مطابع الرسالة، العدد

$$
.1910 \text { (919人 (1.9) }
$$

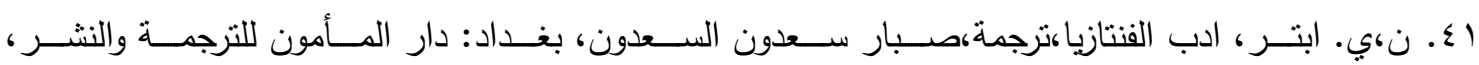
.100 (10) 919 Yع. ارنست كاسير، مقال في الانسان، ترجمة: احسان عباس،بيروت:دار الاندلس للطباعة والنشر، (197 (19، ص

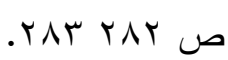
بــ هربرت ريد، تربية الذوق الفني كترجمة كيوسف ميخائيل اسعد، بيروت: دار النهضة العربية للطباعة والنشر ،

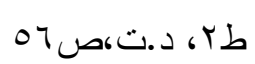

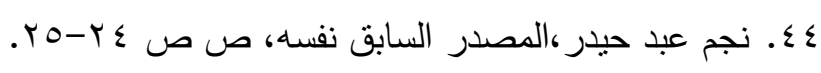

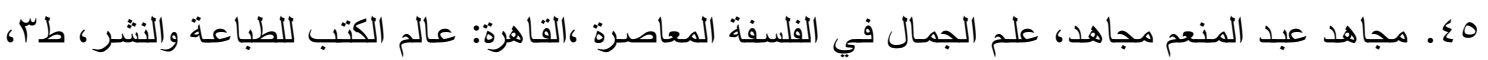

$$
\text { . }
$$

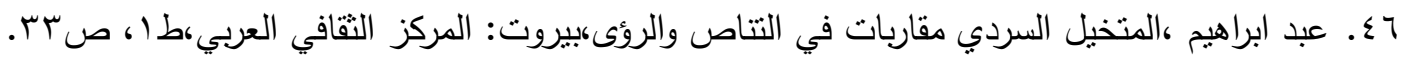

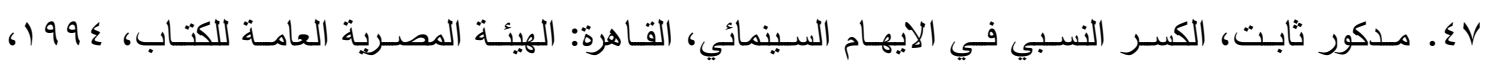

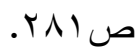

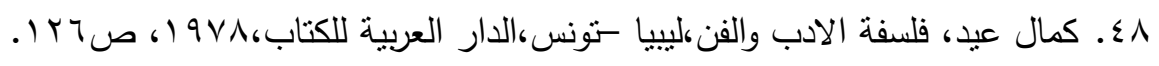

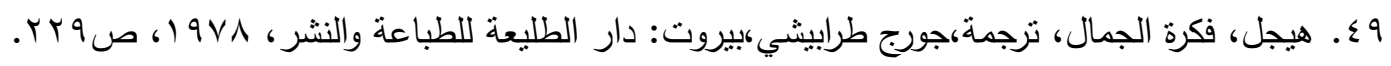




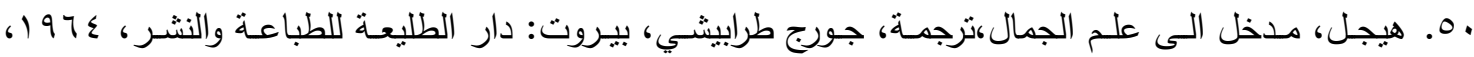

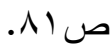

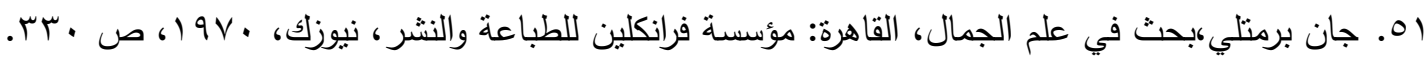

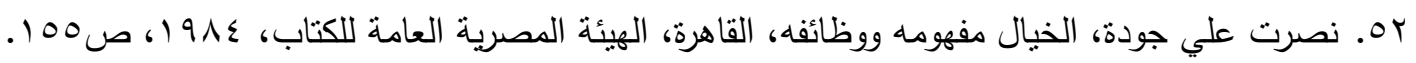
ص

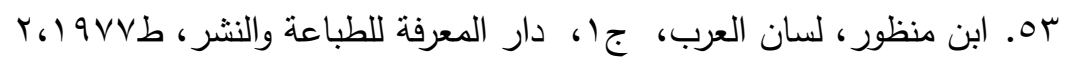
ع.

00. مجموعة من العلماء الاكاديمين السوفيت، الموسوعة الفلسفية الحديثة، ترجمة يوسف كرم، مراجعة جورج

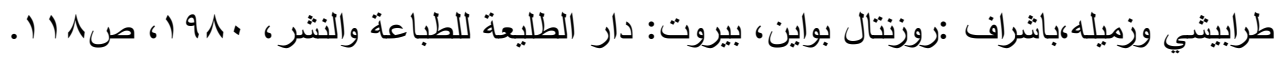
V9

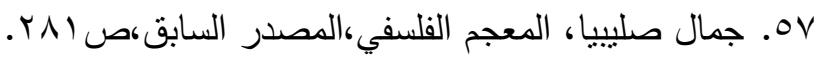

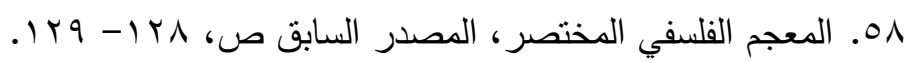

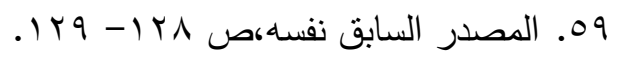
• 7. ر.ل.بريت،التصسور والخيال،ترجمة،عبد الواحد لؤلؤة، بغداد: دار الرشيد،موسوعة المصطلح النقدي، العدد

$$
\text { (10) }
$$

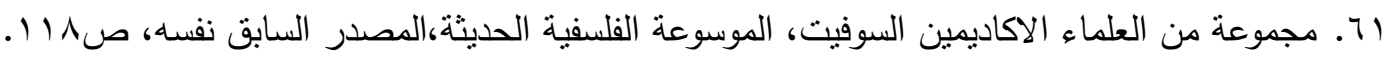

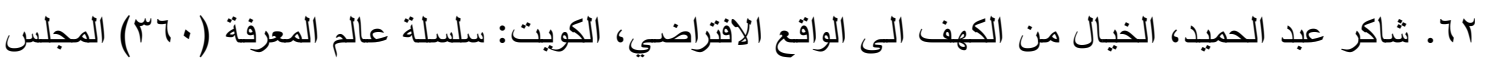

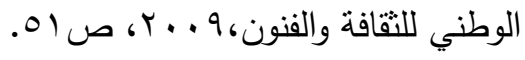

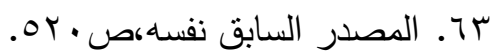

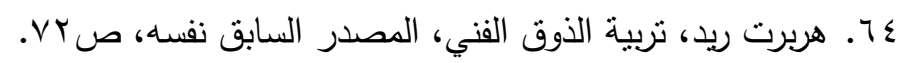

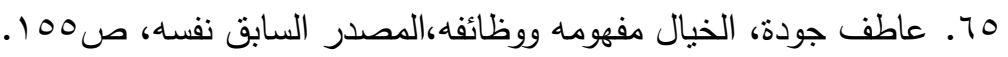

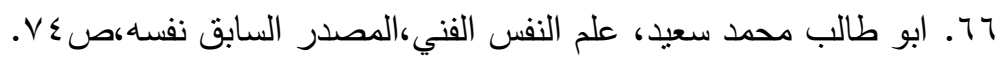

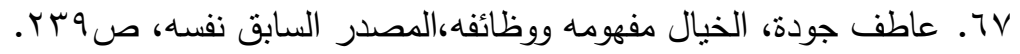

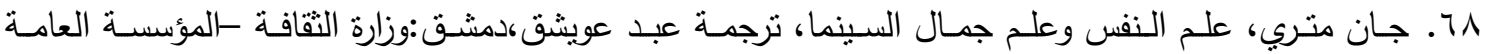

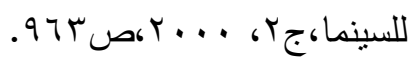
79. شاكر عبد الحميد، الخيال من الكهف الى الواقع الافتراضي،المصدر السابق نفسه، صوَ؟ ا.

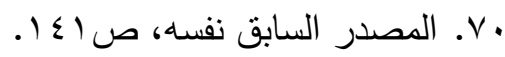




\title{
The mechanism of Cognition and imaginary in art painting M.M. Sahar Abdul-Kadhim Ghanem University of Mustansiriya / Directorate of Technical Activities
}

\begin{abstract}
:
process of forming an integrated vision of art begins in the formation formality symbols consistent in painting, through the formation of the events of compromise and communication between imagination and grasp technical concepts that the artist seeks it in the construction of incomplete formations sensual images perceived by the receiver system, to form the structure conceptual continuous formations sham linked to the imagination, which is owned by the artist and the artwork and the ability of the receiver to decode the painting symbols and expression of the pleasure felt by the sensations through interconnected affect the perception final form of artwork. For this, we find that the process of cognition and imagination qualities go together in the analysis and installation art painting to enjoy these mental processes in the understanding of all the details that the artist seeks delivery to the receiving process. The problem of current research in the following question was formulated - (what how under which that embodied cognition and imagition in art painting) The goal of current research is (What are the modalities in which the cognitive process employs and the imaginary in art painting ) has included theoretical framework following detective first topic perceptions psychology. The second topic - imaginary concept and functions. Section III - the functioning of the imagined mechanism
\end{abstract}

